\title{
ARTICLE
}

\section{MDL-800, an allosteric activator of SIRT6, suppresses proliferation and enhances EGFR-TKIs therapy in non-small cell lung cancer}

\author{
Jia-lin Shang ${ }^{1}$, Shao-bo Ning ${ }^{1}$, Ying-yi Chen ${ }^{1}$, Tian-xiang Chen ${ }^{2}$ and Jian Zhang ${ }^{1,3,4}$
}

\begin{abstract}
Sirtuin 6 (SIRT6), a member of the sirtuin family, is a nicotinamide adenine dinucleotide (NAD ${ }^{+}$)-dependent deacetylase that is involved in various physiological and pathological processes. SIRT6 is generally downregulated and linked to tumorigenesis in non-small cell lung carcinoma (NSCLC), thus regarded as a promising therapeutic target of NSCLC. In this study, we investigated whether MDL-800, an allosteric activator of SIRT6, exerted antiproliferation effect against NSCLC cells in vitro and in vivo. We showed that MDL-800 increased SIRT6 deacetylase activity with an $\mathrm{EC}_{50}$ value of $11.0 \pm 0.3 \mu \mathrm{M} ; \mathrm{MDL}-800(10-50 \mu \mathrm{M})$ induced dose-dependent deacetylation of histone $\mathrm{H} 3$ in 12 NSCLC cell lines. Treatment with MDL-800 dose dependently inhibited the proliferation of 12 NSCLC cell lines with IC 50 values ranging from 21.5 to $34.5 \mu \mathrm{M}$. The antiproliferation effect of MDL-800 was significantly diminished by SIRT6 knockout. Treatment with MDL-800 induced remarkable cell cycle arrest at the $\mathrm{G}_{0} / \mathrm{G}_{1}$ phase in NSCLC HCC827 and PC9 cells. Furthermore, MDL-800 ( $\left.25,50 \mu M\right)$ enhanced the antiproliferation of epidermal growth factor receptor tyrosine kinase inhibitors (EGFR-TKIs) in osimertinib-resistant HCC827 and PC9 cells as well as in patient-derived primary tumor cells, and suppressed mitogen-activated protein kinase (MAPK) pathway. In HCC827 cell-derived xenograft nude mice, intraperitoneal administration of $\mathrm{MDL}-800\left(80 \mathrm{mg} \cdot \mathrm{kg}^{-1} \cdot \mathrm{d}^{-1}\right.$, for $\left.14 \mathrm{days}\right)$ markedly suppressed the tumor growth, accompanied by enhanced SIRT6-dependent histone H3 deacetylation and decreased p-MEK and p-ERK in tumor tissues. Our results provide the pharmacological evidence for future clinical investigation of MDL-800 as a promising lead compound for NSCLC treatment alone or in combination with EGFR-TKIs.
\end{abstract}

Keywords: non-small cell lung cancer; SIRT6 activator; MDL-800; deacetylation; EGFR-TKIs; MAPK; ERK

Acta Pharmacologica Sinica (2021) 42:120-131; https://doi.org/10.1038/s41401-020-0442-2

\section{INTRODUCTION}

Lung cancer is the leading cause of cancer-related morbidity and mortality worldwide $[1,2]$. Small cell lung carcinoma (SCLC) and non-SCLC (NSCLC) are the two major types of lung cancer. NSCLC accounts for $\sim 85 \%$ of all lung cancer cases and is relatively refractory to conventional therapies (surgery, radiation, chemotherapy, and other targeted therapies, including epidermal growth factor receptor tyrosine kinase inhibitors [EGFR-TKIs]) with a low 5-year overall survival rate of $\sim 15 \%$ [3-5]. Thus, there is a pressing need to identify novel targets and develop effective therapeutic agents for NSCLC treatment. Mammalian sirtuins (SIRT1-7) are conserved nicotinamide adenine dinucleotide $\left(\mathrm{NAD}^{+}\right)$-dependent class III deacetylases that play central roles in various biological events, including metabolism, genome stability, longevity, and inflammation. Recently, sirtuins have gained increasing attention as promising targets for the treatment of age-related diseases, including cancers, type 2 diabetes, inflammatory disorders, and Alzheimer's disease [6, 7]. Several chemical modulators of sirtuins that currently exist regulate $\mathrm{NAD}^{+}$levels but lack selectivity. Specific and potent activators or inhibitors of sirtuins will be helpful in cancer therapy by themselves or in combination with different therapies $[6,8]$.

SIRT6 is a member of the sirtuin family, which is responsible for many physiological and pathological processes [9]. Although the function of SIRT6 in cancers is cell context dependent and SIRT6 plays an oncogenic role in some tumors [10-14], the downregulation of SIRT6 has been frequently observed in many cancer types, indicating that SIRT6 functions as a tumor suppressor [15-20]. Emerging studies indicate that the mRNA and protein levels of SIRT6 are generally decreased in NSCLC tissues and cell lines and are closely related to tumor progression and poor prognosis of patients [21, 22]. Overexpression of SIRT6 can suppress NSCLC cell proliferation by inhibiting Twist 1 and induce a radiosensitization effect in NSCLC cells, leading to the induction of $\mathrm{G}_{0} / \mathrm{G}_{1}$ cell cycle arrest and apoptosis $[22,23]$, which is also associated with an improved survival rate among NSCLC patients [24]. Thus, SIRT6 can serve as a promising therapeutic target for NSCLC.

SIRT6 contains a large hydrophobic channel that harbors a substrate with an acetylated lysine and cofactor $\mathrm{NAD}^{+}$, where the

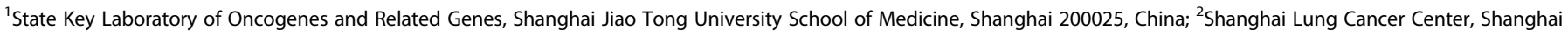

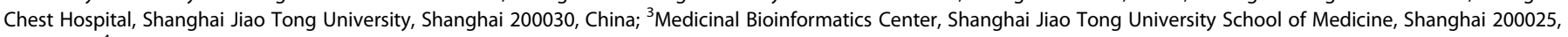
China and ${ }^{4}$ School of Pharmaceutical Sciences, Zhengzhou University, Zhengzhou 450001, China

Correspondence: Tian-xiang Chen (zjutxchen@163.com) or Jian Zhang (jian.zhang@sjtu.edu.cn)

These authors contributed equally: Jia-lin Shang, Shao-bo Ning

Received: 22 March 2020 Accepted: 12 May 2020

Published online: 15 June 2020 
acyl group is removed from the lysine using NAD ${ }^{+}$through SIRT6 deacetylation [25]. In the genomic context, SIRT6 can deacetylate histone $\mathrm{H} 3$ on acetylated K9, K18, and K56 (H3K9Ac, H3K18Ac, and $\mathrm{H} 3 \mathrm{~K} 56 \mathrm{Ac}$ ) [26-28], leading to the transcription inhibition of oncogenic genes, including c-Myc [15], Hif-1a [29], and c-Jun [30], thus implicating SIRT6 in tumorigenesis [15, 17-20, 31]. These findings lead to the hypothesis that pharmacological activation of SIRT6 deacetylation may exert an anticancer effect against NSCLC. Due to the clinical relevance of SIRT6 activation in cancers, many efforts have been directed toward the development of activators of SIRT6. Lamin A and fatty acids have been reported as endogenous activators of SIRT6 to increase deacetylation [32, 33]. To our knowledge, several synthetic small molecules and natural polyphenols have been identified to activate the deacetylation of SIRT6, which has been detected only in vitro [34-36]. Moreover, few potent SIRT6 activators have been reported to elucidate the anticancer efficacy of SIRT6 activation [37, 38]. Using AlloSite [39], we discovered a cellularly active SIRT6 allosteric activator, MDL-800, with high potency and selectivity [37]. It is not yet clear whether a small-molecule SIRT6 activator could be efficient for NSCLC.

Here, we focused on an allosteric activator of SIRT6, MDL-800, as a pharmacological tool to investigate whether it would show antiNSCLC activity. We found that MDL-800 effectively inhibited NSCLC cell proliferation by activating SIRT6 deacetylation and retarding the SIRT6-mediated $\mathrm{G}_{0} / \mathrm{G}_{1}$ cell cycle. Notably, MDL-800 could enhance the antiproliferation of EGFR-TKIs in NSCLC osimertinib-resistant (OR) cells and patient-derived primary tumor cells and inhibit the mitogen-activated protein kinase (MAPK) pathway. Finally, MDL-800 showed favorable in vivo pharmacokinetic profiles and antitumor efficacy against the NSCLC xenograft model. Overall, we demonstrate that the activation of SIRT6 can be a promising therapy in NSCLC with clinical application prospects.

\section{MATERIALS AND METHODS}

Cloning, expression, and purification of wild-type (WT) SIRT6 According to previously described methods [37], WT full-length human SIRT6 was inserted into the pET28a-LIC vector (Addgene plasmid no. 26094). The plasmid was transformed into Escherichia coli BL21(DE3) cells. Protein was purified using a nickel column and gel filtration. Purified protein was dialyzed into the assay buffer (50 $\mathrm{mM}$ Tris- $\mathrm{HCl}$ [pH 8.0], $137 \mathrm{mM} \mathrm{NaCl}, 2.7 \mathrm{mM} \mathrm{KCl}$, and $1 \mathrm{mM} \mathrm{MgCl} 2$ ) and used in all in vitro assays performed in this study.

Synthesis of target compounds

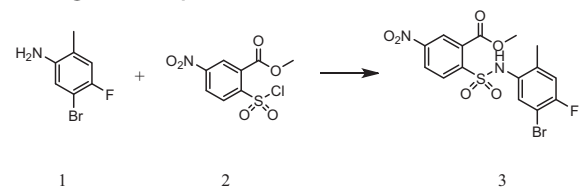

To a solution of 5-bromo-4-fluoro-2-methylaniline (1, $20 \mathrm{~g}, 98.5$ $\mathrm{mmol}$ ) in $50 \mathrm{~mL}$ pyridine was added methyl 2-(chlorosulfonyl)-5nitrobenzoate $(2,33.0 \mathrm{~g}, 118.2 \mathrm{mmol})$ at $0{ }^{\circ} \mathrm{C}$, and the reaction was continuously stirred at $0{ }^{\circ} \mathrm{C}$ for $1 \mathrm{~h}$. Then, the reaction was moved to room temperature and stirred for another $8 \mathrm{~h}$. The reaction was cooled to $0{ }^{\circ} \mathrm{C}$, and the $\mathrm{pH}$ was adjusted to 3-4 with $1 \mathrm{~N}$ hydrochloric acid. The precipitate formed was filtered, washed with water, and dried to yield crude compound, which was directly used in the next step without being purified.

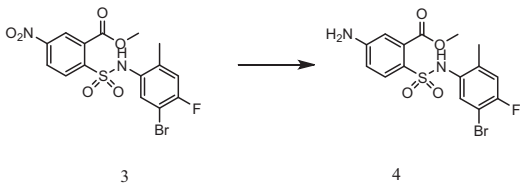

Iron powder ( $14.0 \mathrm{~g}, 250 \mathrm{mmol})$ was added to crude compound $3(38.3 \mathrm{~g}, 85.88 \mathrm{mmol})$ dissolved in acetic acid at room temperature. Then, the reaction was stirred under the same conditions for $12 \mathrm{~h}$. The system was filtered, and the solvent was evaporated under reduced pressure. The solid was dissolved with $400 \mathrm{~mL}$ ethyl acetate and washed with saturated aqueous $\mathrm{NaHCO}_{3}$ brine and dried over sodium sulfate. The organic layer was evaporated in vacuo and subsequently purified by column chromatography on silica gel (PE:EA = 2:1) to afford $4(27.1 \mathrm{~g}$, two steps $66 \%)$ as a white solid.

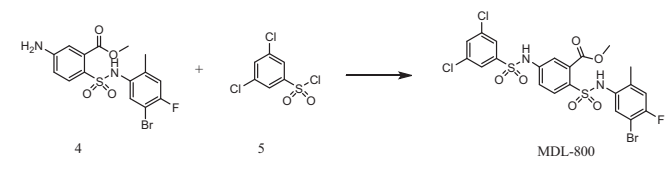

To a solution of methyl 5-amino-2-(N-(5-bromo-4-fluoro-2methylphenyl)sulfamoyl)benzoate $(4,27.1 \mathrm{~g}, 65.2 \mathrm{mmol})$ in 50 $\mathrm{mL}$ pyridine, 3,5-dichlorobenzene-1-sulfonyl chloride $(\mathbf{5}, 19.07 \mathrm{~g}$, $78.2 \mathrm{mmol}$ ) was added at $0{ }^{\circ} \mathrm{C}$, and the reaction was stirred at the same temperature for $\sim 1 \mathrm{~h}$. Then, the reaction was moved to room temperature and stirred for another $6 \mathrm{~h}$. The reaction was cooled to $0{ }^{\circ} \mathrm{C}$, and the $\mathrm{pH}$ was adjusted to 3-4 with $2 \mathrm{~N}$ hydrochloric acid. The precipitate formed was filtered and subsequently purified by column chromatography on silica gel (PE:EA = 3:1) to afford MDL-800 (32.52 g, 80\%) as a white solid. ${ }^{1} \mathrm{H}$ NMR (400 MHz, DMSO-d6) peaks were as follows: $\delta 11.36(\mathrm{~s}$, $1 \mathrm{H}), 9.46(\mathrm{~s}, 1 \mathrm{H}), 8.01(\mathrm{~s}, 1 \mathrm{H}), 7.82-7.81(\mathrm{~d}, J=4.0 \mathrm{~Hz}, 2 \mathrm{H})$ $7.60-7.58(\mathrm{~d}, J=8.0 \mathrm{~Hz}, 1 \mathrm{H}), 7.43-7.41(\mathrm{~m}, 1 \mathrm{H}), 7.28-7.16(\mathrm{~m}, 3 \mathrm{H})$, $3.74(\mathrm{~s}, 1 \mathrm{H})$, and $1.82(\mathrm{~s}, 3 \mathrm{H}) .{ }^{13} \mathrm{C}$ NMR $(100 \mathrm{MHz}, \mathrm{DMSO}-\mathrm{d} 6)$ peaks were as follows: $167.12,158.34,158.91,142.06,141.64,137.89$ $(J=8), 135.87,133.83,133.81,132.60,132.56,132.12(J=3)$, 131.30, 125.81, 120.53, 138.78, 138.62, 138.39, $104.78(J=21)$, 53.64, and 17.32. HRMS (ESI+) $\mathrm{m} / \mathrm{z}$ calculated for $\mathrm{C}_{21} \mathrm{H}_{16} \mathrm{BrCl}_{2} \mathrm{FN}_{2} \mathrm{O}_{6} \mathrm{~S}_{2}(\mathrm{M}+\mathrm{H})^{+}$is 623.8994 and experimentally determined as 624.9072.
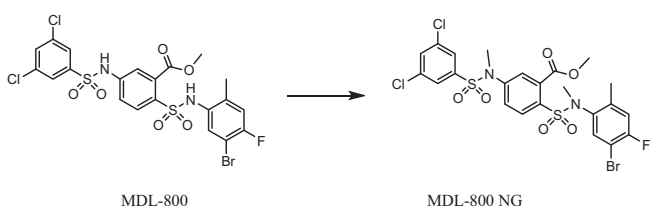

A solution of MDL-800 (100 mg, $0.16 \mathrm{mmol})$ in DMF was stirred at $0{ }^{\circ} \mathrm{C}$. $\mathrm{NaH}(19 \mathrm{mg}, 60 \%, 0.48 \mathrm{mmol})$ was added at the same temperature, and the reaction was stirred for another $1 \mathrm{~h}$ under the same conditions. Then, Mel $(68 \mathrm{mg}, 0.48 \mathrm{mmol})$ was added, and the reaction was moved to room temperature and stirred for another $4 \mathrm{~h}$. Then, $50 \mathrm{~mL}$ ethyl acetate was added to the reaction, and the mixture was washed with saturated aqueous $\mathrm{NaHCO}_{3}$ brine and dried over sodium sulfate. The organic layer was evaporated in vacuo and subsequently purified by column chromatography on silica gel (PE: $E A=3: 1)$ to afford MDL$800 \mathrm{NG}(68 \mathrm{mg}, 63 \%)$ as a white solid. ${ }^{1} \mathrm{H}$ NMR $(500 \mathrm{MHz}$, DMSOd6) peaks were as follows: $\delta 8.09(\mathrm{~s}, 1 \mathrm{H}), 7.68-7.53(\mathrm{~m}, 5 \mathrm{H})$, $7.40-7.38(\mathrm{~d}, J=10 \mathrm{~Hz}, 1 \mathrm{H}), 7.20-7.19(\mathrm{~d}, J=5 \mathrm{~Hz}, 1 \mathrm{H}), 3.66(\mathrm{~s}, 3 \mathrm{H})$, 3.27-3.19 (d, 6H), and $2.11(\mathrm{~s}, 3 \mathrm{H}) .{ }^{13} \mathrm{C}$ NMR $(125 \mathrm{MHz}$, DMSO-d6) peaks were as follows: $166.90,159.14,157.18,144.98,141.14(J=$ 9), 138.82, 136.69, 135.94, 134.31, 134.21, 134.05, 133.65, 130.80, $128.11,126.31,125.35,119.00(J=10), 53.35,39.45,38.04$, and 17.75. LRMS (ESI+) 652.9. HRMS $(\mathrm{ESI}+) \mathrm{m} / \mathrm{z}$ calculated for $\mathrm{C}_{23} \mathrm{H}_{20} \mathrm{BrCl}_{2} \mathrm{FN}_{2} \mathrm{O}_{6} \mathrm{~S}_{2}(\mathrm{M}+\mathrm{H})^{+}$is 651.9307 and experimentally determined as 652.9383. (The HPLC UV spectral purity of MDL-800NG was $>95 \%$.) The synthesis and spectral data of MDL-800 were the same as previously reported [37]. The spectral data for MDL-800NG are depicted in Supplementary Information Fig. S1. 
<smiles>COC(=O)c1cc(F)c(Br)cc1NS(=O)(=O)c1ccc(NS(=O)(=O)c2ccc(N)cc2C(=O)OC)cc1C(=O)OC</smiles><smiles>COC(=O)c1cc(NS(=O)(=O)c2cc(Cl)cc(Cl)c2)ccc1S(=O)(=O)Nc1cc(Br)c(F)cc1C</smiles>

MDL- 800<smiles>COC(=O)c1cc(N(C)S(=O)(=O)c2cc(Cl)cc(Cl)c2)ccc1S(=O)(=O)N(C)c1cc(Br)c(F)cc1C</smiles>

MDL-800NG

Scheme 1 The synthetic procedures of MDL-800 and MDL-800NG. Reagents: a pyridine, room temperature; $\mathbf{b} \mathrm{Fe}, \mathrm{CH}_{3} \mathrm{COOH}, 50{ }^{\circ} \mathrm{C} ; \mathbf{c}$ pyridine, room temperature; $\mathbf{d ~ N a H}, \mathrm{Mel}, \mathrm{DMF}, 0^{\circ} \mathrm{C}$ to room temperature.

Fluor de Lys (FDL) assay

WT SIRT6 protein $(5 \mu \mathrm{M})$ was incubated in a $50-\mu \mathrm{L}$ reaction mixture (2.5 mM NAD ${ }^{+}, 75 \mu \mathrm{M}$ RHKK-Ac-AMC, compounds/DMSO, and assay buffer) at $37^{\circ} \mathrm{C}$ for $2 \mathrm{~h}$; the reaction was stopped by $40 \mathrm{mM}$ nicotinamide, and the mixture was incubated with $6 \mathrm{mg} / \mathrm{mL}$ trypsin for $30 \mathrm{~min}$ at $25^{\circ} \mathrm{C}$. The fluorescence intensity was measured with a microplate reader (Synergy H4 Hybrid Reader, BioTek) at excitation and emission wavelengths of 360 and $460 \mathrm{~nm}$, respectively. $\mathrm{EC}_{50}$ values were calculated by fitting the data points with the dose-response function in GraphPad Prism V7. Each experiment was independently performed three times in technical triplicates.

\section{Clinical sample collection}

Clinical patient samples were collected in the Shanghai Lung Cancer Center, Shanghai Chest Hospital, Shanghai Jiao Tong University School of Medicine. Individual NSCLC tissue was isolated from a 45year-old female patient diagnosed with pulmonary invasive adenocarcinoma of the left lower lobe in 2019. The study was approved by the Ethics Committee of Shanghai Chest Hospital, Shanghai Jiao Tong University School of Medicine. Informed written consent was obtained from the patient.

Cell culture

All NSCLC cell lines were obtained from the Cell Resource Center of the Shanghai Institute for Biological Sciences, Chinese
Academy of Sciences. The NCl-H358, NCl-H1299, NCl-H1650, $\mathrm{NCl}-\mathrm{H} 23, \mathrm{NCl}-\mathrm{H} 1792, \mathrm{NCl}-\mathrm{H} 520, \mathrm{NCl}-\mathrm{H} 460, \mathrm{NCl}-\mathrm{H} 1975, \mathrm{HCC} 827$, and PC9 cell lines were maintained in RPMI-1640 medium supplemented with $10 \%(\mathrm{v} / \mathrm{v})$ fetal bovine serum (FBS) (Invitrogen). Calu- 1 cells were maintained in McCoy's $5 \mathrm{~A}$ modified medium supplemented with $10 \%(\mathrm{v} / \mathrm{v})$ FBS. A549 cells were maintained in F-12K medium supplemented with $10 \%(\mathrm{v} / \mathrm{v}) \mathrm{FBS}$. All cell lines were cultured according to the standard cell culturing protocols of the American Type Culture Collection and were maintained in a humidified $37^{\circ} \mathrm{C}$ incubator with $5 \% \mathrm{CO}_{2}$. The cell lines were authenticated by short tandem repeat profiling.

\section{Establishment of OR NSCLC cells}

OR HCC827 and NCl-H1975 cells were established and maintained as described previously [40-42]. In short, $1 \times 10^{6} \mathrm{HCC} 827$ or $\mathrm{NCl}$ $\mathrm{H} 1975$ cells $/ \mathrm{mL}$ were seeded in a six-well plate and incubated in RPMI-1640 medium containing osimertinib (TargetMol, China). Cells were grown in culture medium containing increasing concentrations of osimertinib for $72 \mathrm{~h}$ with a recovery period between treatments. After 6 months of passage, the remaining $\mathrm{HCC} 827$ or $\mathrm{NCl}-\mathrm{H} 1975$ cells that grew in the presence of 1 or $4 \mu \mathrm{M}$ osimertinib, respectively, were considered OR cells, while the parental $\mathrm{NCl}-\mathrm{H} 1975$ and $\mathrm{HCC} 827$ cell lines were only maintained in osimertinib-free medium. 
a<smiles>[R]N(c1ccc(S(=O)(=O)N([R])c2cc(Br)c(F)cc2C)c(C(=O)OC)c1)S(=O)(=O)c1cc(Cl)cc(Cl)c1</smiles>

b

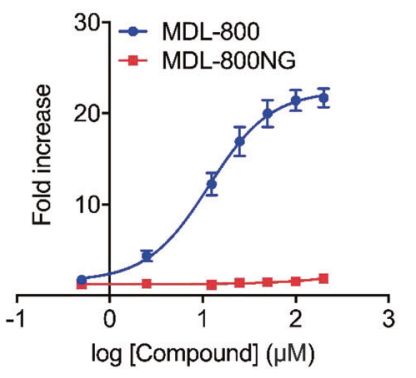

C

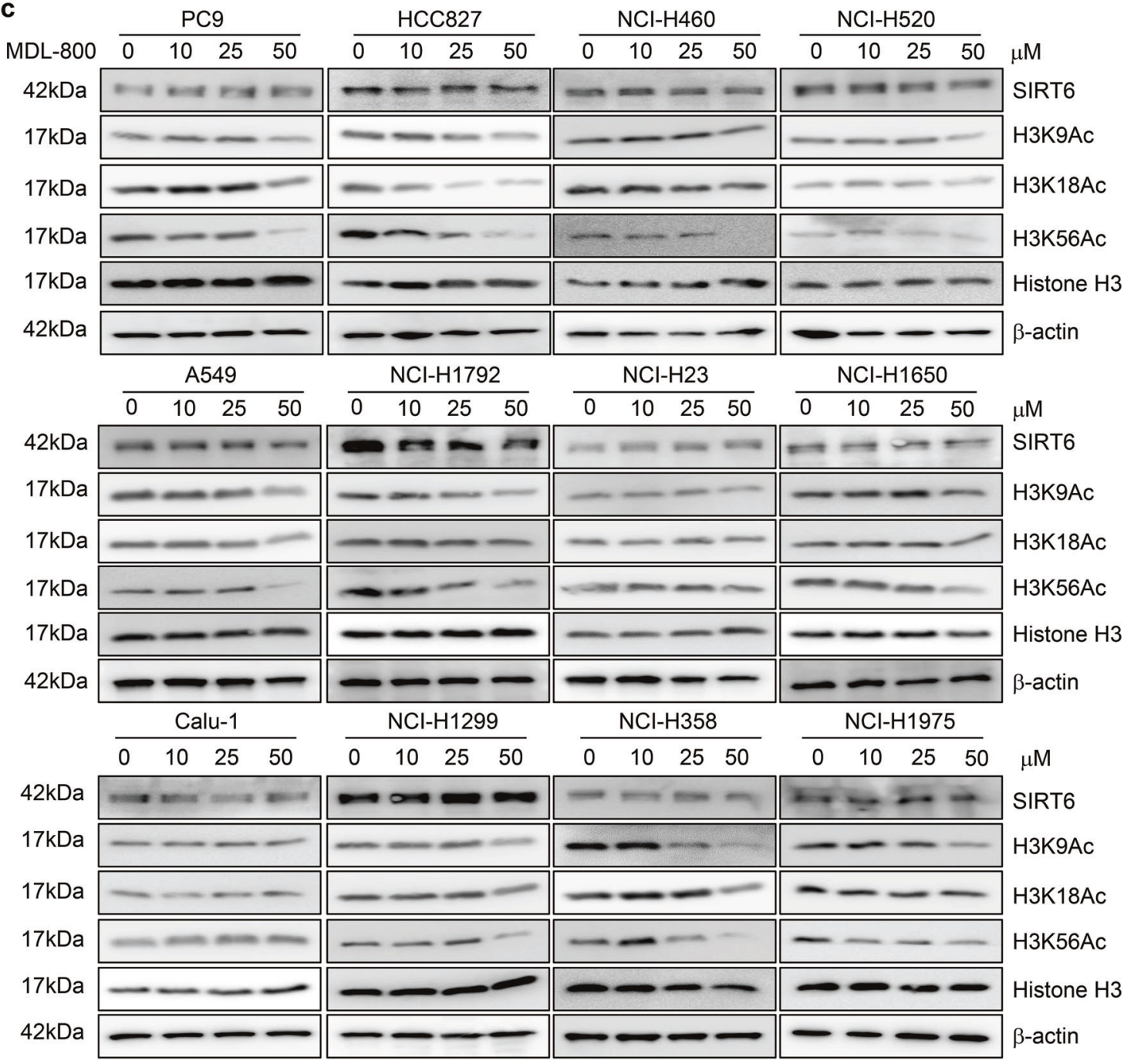

Fig. 1 MDL-800 activates histone H3 deacetylation of SIRT6 in NSCLC cells. a Chemical structure of MDL-800 and MDL-800NG. b Concentration-dependent effects of MDL-800 and MDL-800NG on the activation of SIRT6 deacetylation were assessed by FDL assays with the acetylated peptide RHKK-Ac-AMC $(75 \mu \mathrm{M})$. The data are shown as the mean \pm SD from three or four independent experiments (MDL-800: $\left.\mathrm{EC}_{50}=11.0 \pm 0.3 \mu \mathrm{M}\right)$. c Dose-dependent deacetylation effects of MDL-800 in NSCLC cell lines. Western blots of SIRT6, H3K9Ac, H3K18Ac, and $\mathrm{H} 3 \mathrm{~K} 56 \mathrm{Ac}$ levels in various NSCLC cell lines treated with the indicated concentrations of MDL- $800 \mathrm{for} 48 \mathrm{~h}$. Histone $\mathrm{H} 3$ was used as the internal control, and $\beta$-actin was used as the loading control.

Isolation and culture of patient-derived primary NSCLC cells Patient-derived primary NSCLC cells were isolated from a 45-yearold female patient diagnosed with pulmonary invasive adenocarcinoma of the left lower lobe in 2019. The tissues were cut into small blocks of $\sim 1 \mathrm{~mm}^{3}$ and washed extensively in PBS. Then, the small pieces were digested with $1 \mathrm{mg} / \mathrm{mL}$ collagenase I (Solarbio, China) for $3 \mathrm{~h}$ at $37^{\circ} \mathrm{C}$. Digested tissues were centrifuged at $400 \times$ $g$ for $5 \mathrm{~min}$, and the pellet was washed in PBS and passed through a $70 \mu \mathrm{m}$ sterile cell strainer (Corning, USA).The isolated cells were cultured in RPMI-1640 supplemented with $10 \% \mathrm{FBS}, 100 \mathrm{U} / \mathrm{mL}$ penicillin, and $100 \mathrm{~g} / \mathrm{mL}$ streptomycin (Invitrogen, USA) in a humidified atmosphere $\left(37^{\circ} \mathrm{C}, 5 \% \mathrm{CO}_{2}\right)$ and were used within two or three passages.

Cell viability

Cell viability was evaluated using a Cell Counting Kit-8 (CCK-8) (Dojindo), following the manufacturer's instructions. Briefly, NSCLC cells were seeded ( $n=3$ wells/group) in 96-well plates at a density 


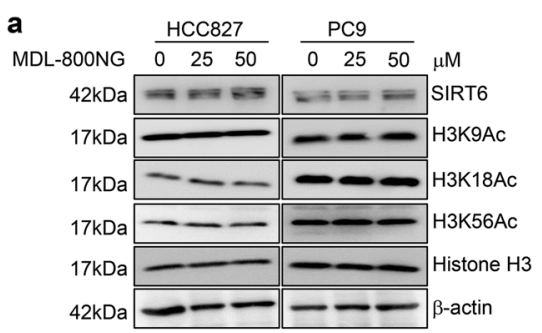

b

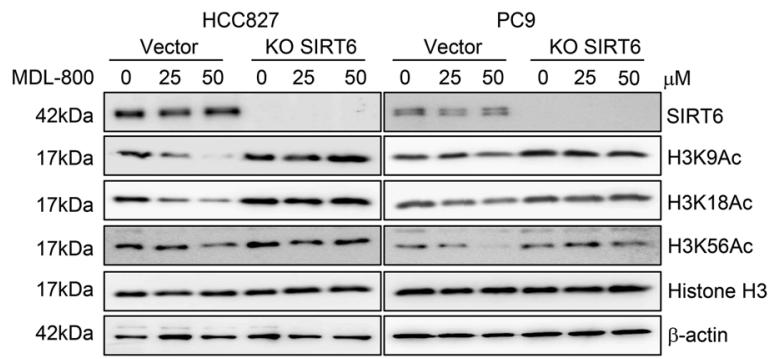

Fig. 2 MDL-800 activates histone $\mathrm{H3}$ deacetylation of SIRT6 in NSCLC cells. a Western blots of SIRT6, H3K9AC, H3K18AC, and $\mathrm{H} 3 \mathrm{~K} 56 \mathrm{Ac}$ levels in HCC827 and PC9 cells treated with the indicated concentrations of MDL-800NG for $48 \mathrm{~h}$. b Western blots of SIRT6, H3K9Ac, H3K18Ac, and H3K56Ac levels in vector or SIRT6-KO HCC827 and PC9 cells treated with the indicated concentrations of MDL-800 for $48 \mathrm{~h}$. Histone $\mathrm{H} 3$ was used as the internal control, and $\beta$-actin was used as the loading control.

of $5 \times 10^{3}$ cells per well. After attaching overnight, NSCLC cells were treated with MDL-800 at various concentrations. Cells treated with DMSO were used as positive controls. After $48 \mathrm{~h}$ of treatment, CCK-8 $\left(10 \mu \mathrm{L} /\right.$ well) was added and incubated for $1 \mathrm{~h}$ at $37^{\circ} \mathrm{C}$. To measure the number of viable cells, the absorbance of each well was detected at $450 \mathrm{~nm}$ using a microplate reader (Synergy $\mathrm{H} 4$ Hybrid Reader, BioTek). The relative viability of each group is presented as the percentage change relative to the positive control group. Each data point is the mean \pm SD of two or three independent experiments.

Colony formation

Cells at a density of 300 cells/well were plated into six-well plates and cultured in RPMI-1640 medium. Medium containing different concentrations of MDL-800 or MDL-800NG (25 or $50 \mu \mathrm{M}$ ) and DMSO (control) was replaced every 2 days. After 10 days, colonies were fixed with methanol and stained with crystal violet (Beyotime) for $30 \mathrm{~min}$. Finally, plates were washed gently with water, images were captured with a Nikon Ti-S microscope, and colony numbers were quantified by ImageJ V4.

Immunoblotting and antibodies

Cells $\left(2 \times 10^{5}-3 \times 10^{5}\right.$ cells) were seeded in six-well plates and treated with DMSO, MDL-800, or MDL-800NG. After $48 \mathrm{~h}$ of treatment, both floating and adherent cells were lysed with $1 \times$ SDS buffer and separated by SDS-PAGE, followed by incubation with specific primary antibodies overnight at $4{ }^{\circ} \mathrm{C}$ and then with HRP-conjugated anti-rabbit lgG (\#7074, Cell Signaling Technology) or anti-mouse IgG (\#7076, Cell Signaling Technology). An Immobilon Western Chemiluminescent HRP Substrate Kit (Millipore) was used for detection. Information regarding the primary antibodies is shown in Supplementary Information Table S4.

Generation of CRISPR-Cas9 knockout cell lines

SIRT6-KO NSCLC cell lines were generated following a previous protocol [43]. In brief, sgRNA targeting exon 1, CACTTG CCCTTGTCCGCGTACGG (with the PAM underlined), was cloned into the lentiCRISPR v2 vector (Addgene plasmid no. 52961). The lentivirus was generated by transfecting the lentiCRISPR v2 vector containing sgRNA, psPAX2, and pMD2.G into HEK293T cells using Neofect ${ }^{\mathrm{TM}}$ DNA transfection reagent, following the manufacturer's protocol. The viral supernatant was collected $48 \mathrm{~h}$ after transfection and used to infect the indicated cells with $8 \mu \mathrm{g} / \mathrm{mL}$ polybrene (Sigma-Aldrich). Then, the virally infected cells were selected in medium containing puromycin (Sigma-Aldrich). Total protein was isolated from single cell-derived colonies and assessed by Western blotting.

Cell cycle analysis

Cells were seeded in six-well plates. After $24 \mathrm{~h}$ of seeding, cells were treated with DMSO, MDL-800, or MDL-800NG for $48 \mathrm{~h}$. Then, both floating and adherent cells were collected and fixed with $75 \%$ ethanol at $4{ }^{\circ} \mathrm{C}$ overnight. Cells were incubated with RNase I $(50 \mu \mathrm{g} / \mathrm{mL})$ in $1 \times$ PBS at $37^{\circ} \mathrm{C}$ for $30 \mathrm{~min}$ and stained with PI (propidium iodide) $(50 \mu \mathrm{g} / \mathrm{mL})$ for $15 \mathrm{~min}$. Cells were assessed by flow cytometry and FACS DIVA software, v6.2 (BD Biosciences). The cell cycle distribution was analyzed using FlowJo 7.6.1 software.

RNA extraction and RT-qPCR

Total RNA was extracted from NSCLC cells using TRIzol reagent (Invitrogen), according to the manufacturer's instructions. Then, 1 $\mu \mathrm{g}$ of total RNA was reverse transcribed to CDNA using a FastKing RT Kit (Tiangen). The cDNA was amplified in triplicate using SYBR Green Master Mix (Roche) in an ABI 7900 Thermal Cycler (Applied Biosystems), following the manufacturer's instructions. Mean cycle threshold $(\mathrm{Ct})$ values were used for the expression analysis. The mRNA levels of target genes were calculated by the $2^{-\Delta \Delta C t}$ method. The expression data were normalized to $\beta$-actin expression levels and presented as the mean \pm SEM of three independent experiments. The RT-qPCR primer sequences are listed in Supplementary Information Table S5.

Combination drug treatment

Gefitinib, afatinib, and osimertinib were purchased from TargetMol. For cell viability assays, all drugs were dissolved in DMSO, stored at $-20^{\circ} \mathrm{C}$, and protected from light. The maximum final DMSO concentration was less than $0.25 \%$. Cells were treated with MDL-800 at concentrations ranging from 25 to $50 \mu \mathrm{M}$ with gefitinib, afatinib, or osimertinib at the indicated concentrations. Then, cell viability assays were conducted using the CCK-8 method. Combination effects were analyzed by the Chou-Talalay combination index $(\mathrm{Cl})$ method [44]. The $\mathrm{Cl}$ and the fraction of cells affected values were generated using CompuSyn Version 1.0 software. $\mathrm{Cl}$ values of $<1,=1$, and $>1$ indicate synergism, additivity, and antagonism between the drugs, respectively.

Pharmacokinetic studies in mice

Pharmacokinetic studies were performed by BioDuro Inc., Shanghai, China, according to the standard protocol. Six-weekold male C57BL/6J mice were grouped randomly $(n=5$ mice per group) and administered MDL-800 by a single intravenous (IV) bolus at a dose of $45 \mathrm{mg} / \mathrm{kg}$, intraperitoneal (IP) injection at a dose of $65 \mathrm{mg} / \mathrm{kg}$, or oral gavage (PO) at a dose of $90 \mathrm{mg} / \mathrm{kg}$. Three administration formulations were prepared in the vehicle with $5 \%$ DMSO, 30\% PEG-400, and 65\% saline, and the $\mathrm{pH}$ was adjusted to 7.0-8.0. After treatment, mice were sacrificed, and plasma samples were harvested at $5 \mathrm{~min}, 15 \mathrm{~min}, 30 \mathrm{~min}, 1 \mathrm{~h}, 2 \mathrm{~h}, 4 \mathrm{~h}, 8 \mathrm{~h}$, and $24 \mathrm{~h}$. The drug concentration in plasma was analyzed by LC-MS/MS. Pharmacokinetic parameters were calculated using Analyst Software 1.6.3 from mean plasma concentration-time profiles. The area under the curve (AUC) was calculated from the time versus concentration data by the linear trapezoidal rule. The IP/PO bioavailability was calculated as the ratio of AUC for MDL-800 from IP/PO and IV dosages. The calculation was normalized to relative doses. 
a

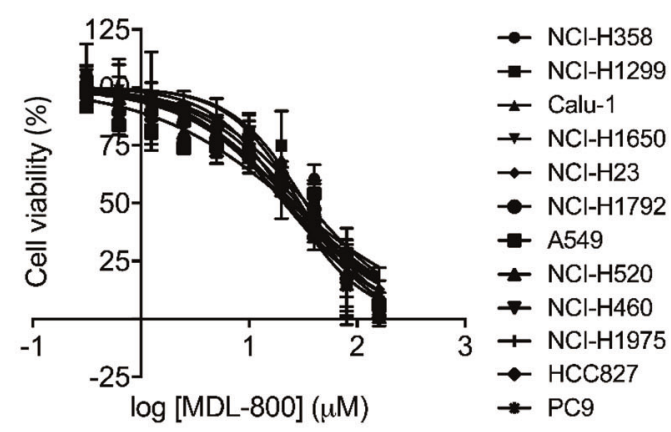

C

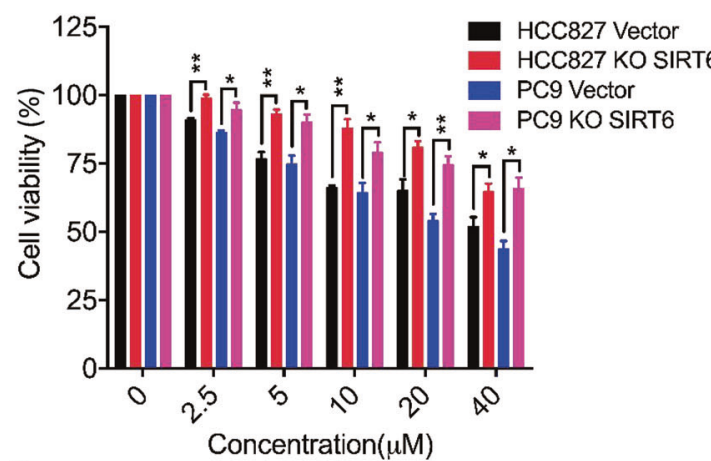

e

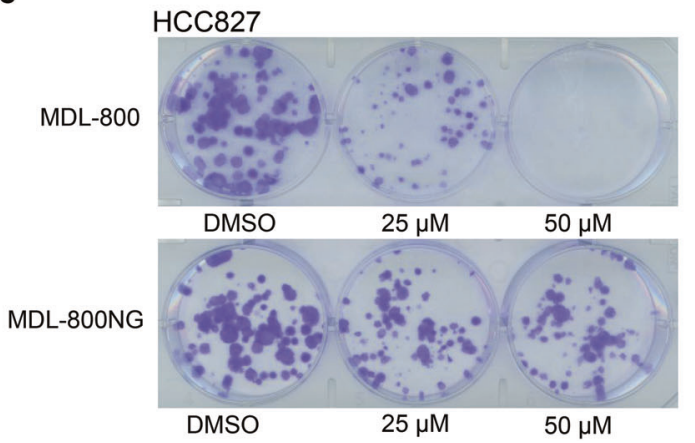

b

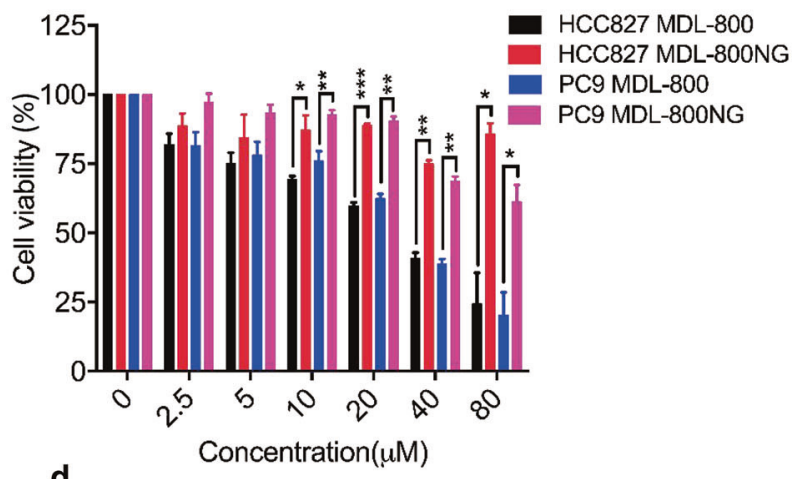

d
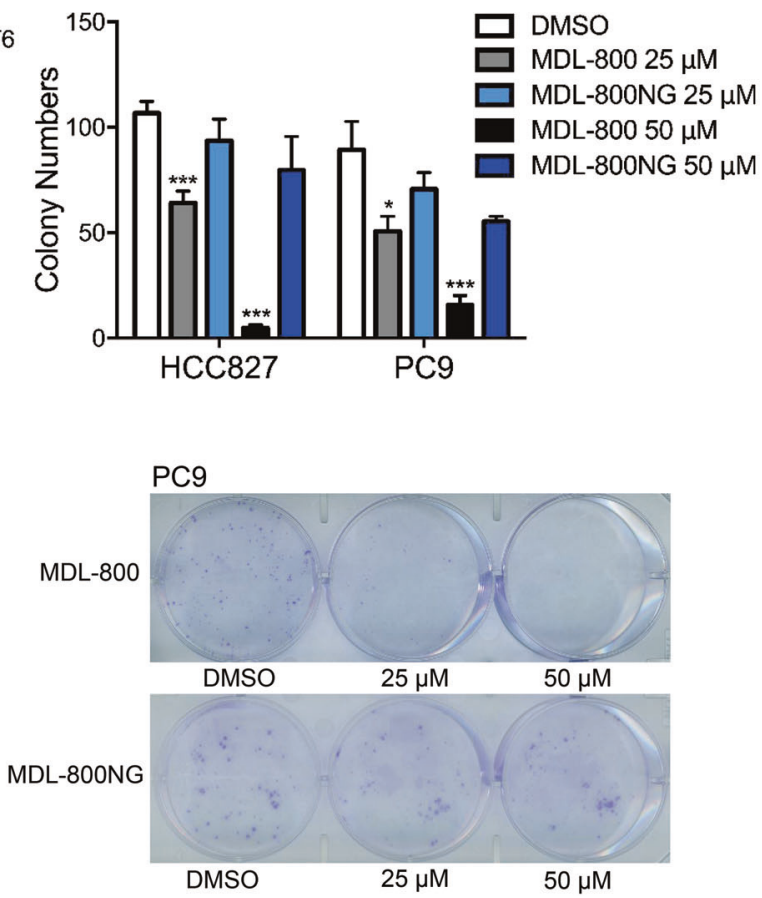

Fig. 3 MDL-800 extensively inhibits NSCLC cell proliferation. a Dose response of the viability of various NSCLC cell lines exposed to MDL800 for 48 h. Cell viability was determined by the CCK-8 assay. The viability of the drug treatment groups was normalized to the viability of the corresponding DMSO-treated controls. The points indicate the mean \pm SD of three independent experiments. $\mathbf{b}$ Dose response of the viability of HCC827 and PC9 cells exposed to MDL-800 or MDL-800NG for $48 \mathrm{~h}$. Relative viability was normalized to that of the DMSO controls. Error bar, SEM of three replicates. c Dose response of the viability of vector or SIRT6-KO HCC827 and PC9 cells exposed to MDL-800. Error bar, SEM of three replicates. d The colony formation of HCC827 and PC9 cells treated with DMSO, MDL-800, or MDL-800NG for 10 days was analyzed. The cell colonies were stained with crystal violet and counted. The statistical analysis of the colony formation assay is shown (mean \pm SEM). e Representative images of the colony formation of HCC827 and PC9 cells treated with DMSO, MDL-800, or MDL-800NG. All $P$ values were determined by a two-tailed unpaired Student's $t$ test $\left({ }^{*} P<0.05 ;{ }^{*} P<0.01 ;{ }^{* *} P<0.001\right)$.

Human NSCLC cell-derived xenograft (CDX) studies

The HCC827 CDX model was established by following federal and institutional guidelines approved by the Institutional Animal Care and Use Committee at Shanghai Jiao Tong University School of Medicine. To establish the CDX, HCC827 cells $\left(1 \times 10^{6}\right)$ suspended in $100 \mu \mathrm{L}$ of $1 \times$ PBS were injected subcutaneously into the flanks of 6-week-old male BALB/c nude mice. Mice were monitored daily, and caliper measurements began when tumors became visible. The tumor volumes were measured every other day using calipers. Then, tumor volumes were calculated using the following formula: $\left(L \times W^{2}\right) / 2$, where $L$ and $W$ refer to the length and width of tumors, respectively. When the mean tumor volume was $\sim 100 \mathrm{~mm}^{3}$, mice were randomly grouped $(n=5)$, and treatment was initiated. Mice received an IP injection of the vehicle alone (5\% DMSO, 30\% PEG400 , and $65 \%$ saline, $\mathrm{pH} 7.0-8.0$ ) or designated doses of MDL-800 every other day for 14 days. The tumor volumes and body weights of the mice were monitored every other day. After treatment or if meeting the humane endpoint criteria, the mice were sacrificed by $\mathrm{CO}_{2}$ asphyxiation. Tumors were dissected, photographed, and weighed. Tumor tissues were collected and fixed in $10 \%$ neutral buffered formalin or snap frozen in liquid $\mathrm{N}_{2}$ and stored at $-80^{\circ} \mathrm{C}$ for the following analyses.

Histological and immunohistochemical (IHC) analyses Xenograft tumor tissues were fixed in $4 \%$ paraformaldehyde for $24 \mathrm{~h}$, embedded in paraffin, and sectioned with a semiautomated rotary microtome (Leica, RM2235). Morphology was evaluated by hematoxylin and eosin (H\&E) staining. The protein levels were analyzed by immunohistochemistry using standard protocols with specific primary antibodies (anti-H3K9Ac, 1:100 dilution, ab32129, Abcam; anti-p-ERK, 1:400 dilution, 4370, Cell Signaling Technology; anti-ERK, 1:500 dilution, 4696, Cell Signaling 

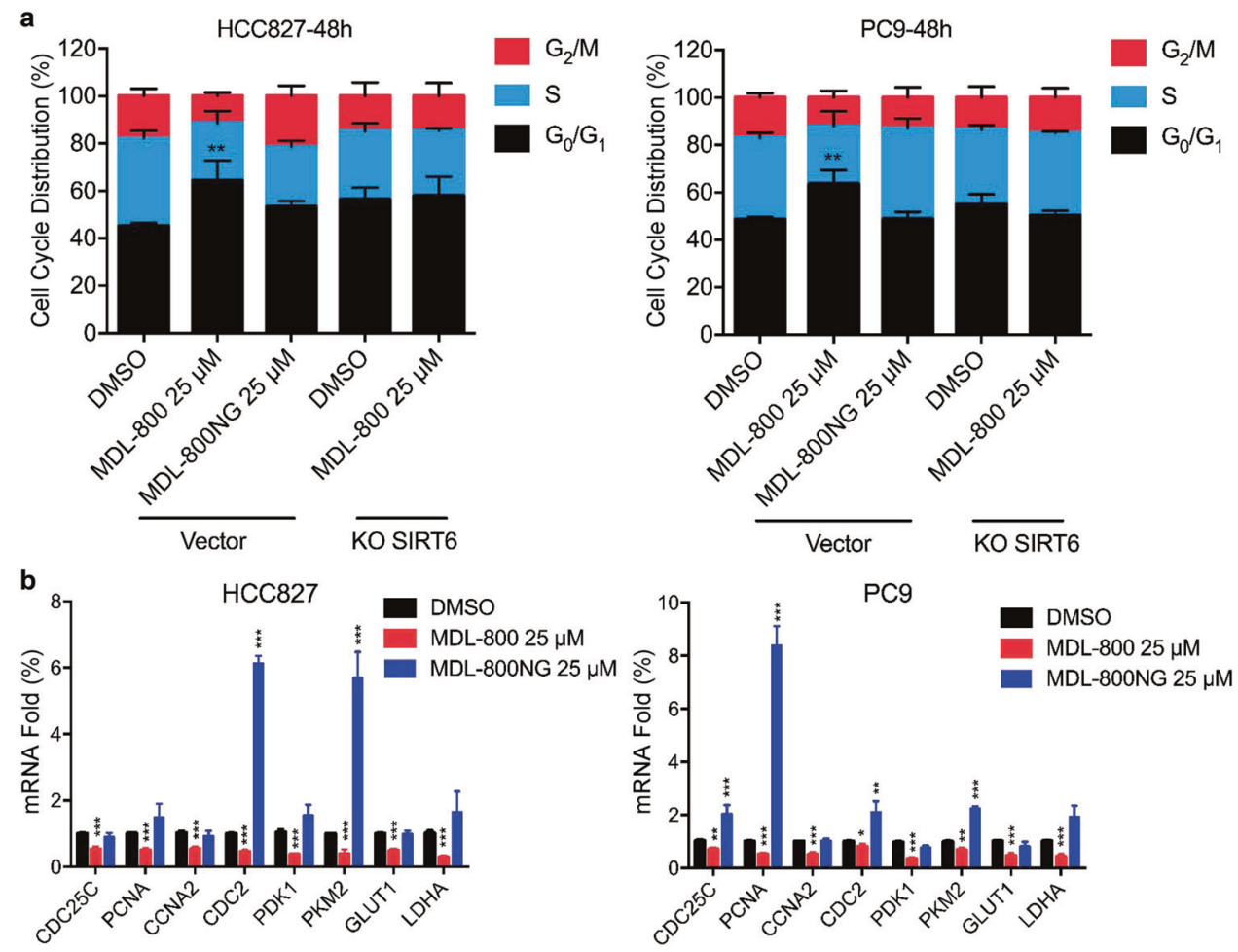

Fig. 4 MDL-800 induces cell cycle arrest in NSCLC cells. a Cell cycle distribution of HCC827 and PC9 cells treated with DMSO, $25 \mu \mathrm{M}$ MDL800 , or MDL-800NG for $48 \mathrm{~h}$, and vector or SIRT6-KO HCC827 and PC9 cells exposed to DMSO and $25 \mu \mathrm{M}$ MDL-800 for $48 \mathrm{~h}$ were measured by PI staining. The data are presented as the mean \pm SD of three independent experiments $(* * P<0.01$, two-way ANOVA). $\mathbf{b}$ RT-qPCR analyses showing the mRNA levels of candidate genes in HCC827 and PC9 cells treated with DMSO, $25 \mu \mathrm{M} \mathrm{MDL-800,} \mathrm{or} \mathrm{MDL-800NG} \mathrm{for} 48 \mathrm{~h}$. The data are normalized to $\beta$-actin levels and presented as the mean \pm SEM of three independent experiments. $P$ values were determined by a twotailed unpaired Student's $t$ test $\left({ }^{*} P<0.05 ;{ }^{* *} P<0.01 ;{ }^{* * *} P<0.001\right.$, compared with the DMSO-treated group).

Technology; and anti-Ki-67, 1:200 dilution, ab15580, Abcam). All assays were followed by staining with an HRP-conjugated secondary antibody (anti-mouse, KIT-9702; anti-rabbit, KIT-9707, Maixin Biotechnology), and samples were then counterstained with H\&E and mounted. Images were captured with a Nikon Ti-S microscope.

Statistical analysis

All data were analyzed using Microsoft Office Excel 2016 and GraphPad Prism V7. The graphs and error bars show the mean \pm SD of independent biological experiments unless stated otherwise. Statistical analysis was performed using two-tailed Student's $t$ tests or ANOVA unless stated otherwise. $P<0.05$ was considered statistically significant $\left({ }^{*} P<0.05 ;{ }^{*} P<0.01 ;{ }^{* *} P<0.001\right)$. The investigators were not blinded to each experiment.

\section{RESULTS}

MDL-800 activates histone $\mathrm{H} 3$ deacetylation of SIRT6 in NSCLC cells

SIRT6 has been considered a promising therapeutic target in NSCLC $[21,22]$. Having a potent and specific SIRT6 activator may provide a unique opportunity to explore whether SIRT6 activation can be useful as an anti-NSCLC strategy. We have identified the cellularly active allosteric activator of SIRT6, MDL-800 [37]. To facilitate further investigation of MDL-800 in NSCLC cells, we synthesized the corresponding MDL-800NG as an inactivating control of MDL-800. MDL-800NG differs from MDL-800 by only two groups (the two $\mathrm{H}$ atoms in MDL-800 are changed to methyl groups in MDL-800NG) (Scheme 1 and Fig. 1a). FDL assays with an acetylated peptide (RHKK-Ac-AMC) [37] showed that MDL-800 activated SIRT6 deacetylation with a half-maximal effective concentration $\left(\mathrm{EC}_{50}\right)$ value of
$11.0 \pm 0.3 \mu \mathrm{M}$, while MDL-800NG did not activate SIRT6 deacetylase activity even up to $200 \mu \mathrm{M}$ (Fig. 1b). Next, we evaluated the cellular histone $\mathrm{H} 3$ deacetylase activity of SIRT6 after MDL-800 treatment in 12 various NSCLC cell lines. As shown by Western blots in Fig. 1C, MDL-800 could induce dose-dependent deacetylation of SIRT6targeted histone H3 in NSCLC cell lines. In the sensitive HCC827 and PC9 cell lines, MDL-800 markedly enhanced histone H3 deacetylation of SIRT6 in a dose-dependent manner, but there was little effect observed in cells treated with the negative control MDL-800NG (Fig. 2a). To further investigate the target engagement of MDL-800 in NSCLC cells, we generated SIRT6-knockout (SIRT6-KO) HCC827 and PC9 cell lines using the CRISPR/Cas9 system. As expected, the activating deacetylation effect of MDL- 800 was not appreciable in SIRT6-KO NSCLC cells compared with control vector cells (Fig. 2b), indicating that MDL-800 activates SIRT6-specific histone $\mathrm{H} 3$ deacetylation in NSCLC cells.

MDL-800 extensively inhibits NSCLC cell proliferation Increasing studies have demonstrated that SIRT6 can suppress tumorigenesis by reducing the levels of H3K9AC and H3K56AC $[15,17-20,31]$. To explore whether this association has a pharmacological effect on NSCLC tumorigenesis, we assessed the antiproliferation of MDL-800 in 12 different NSCLC cell lines. We found that MDL-800 significantly reduced the proliferation of various NSCLC cell lines in a dose-dependent manner (Fig. 3a), with half-maximum inhibitory concentration $\left(\mathrm{IC}_{50}\right)$ values at $48 \mathrm{~h}$ ranging from 21.5 to $34.5 \mu \mathrm{M}$ (Supplementary Information Table S1), whereas MDL-800NG did not significantly affect the proliferation of NSCLC cells up to $80 \mu \mathrm{M}$ (Fig. 3b). Similarly, SIRT6-KO HCC827 and PC9 cells became more resistant to MDL-800 than the vector control groups (Fig. 3c), supporting that MDL-800 inhibits the proliferation of NSCLC cells by activating SIRT6 specifically. We 
a
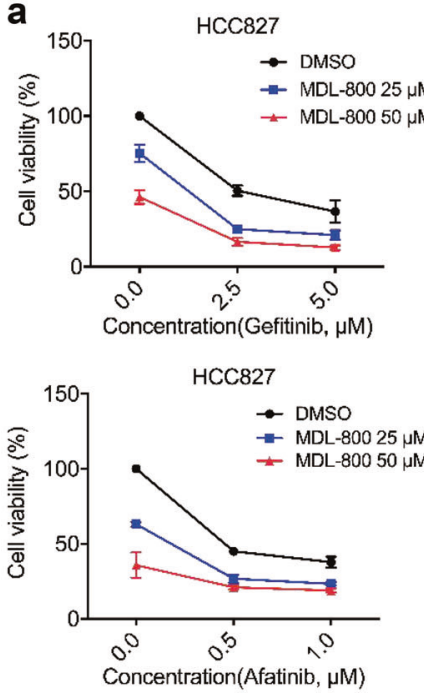

HCC827

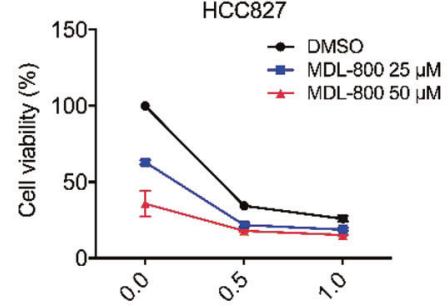

b

Concentration(Osimertinib, $\mu \mathrm{M}$ )

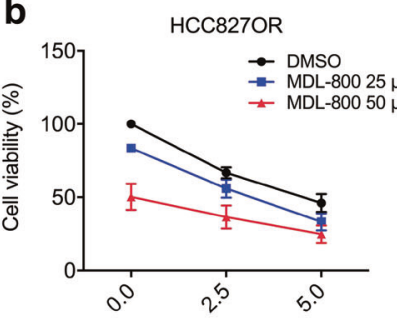

Concentration(Osimertinib, $\mu \mathrm{M}$ )

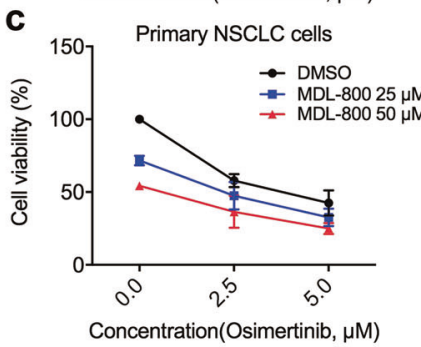

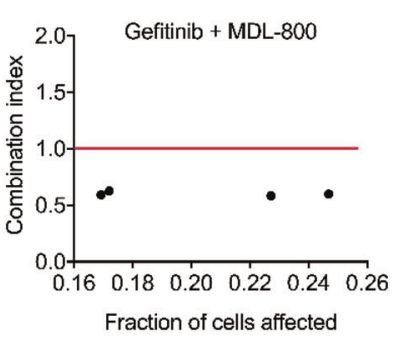

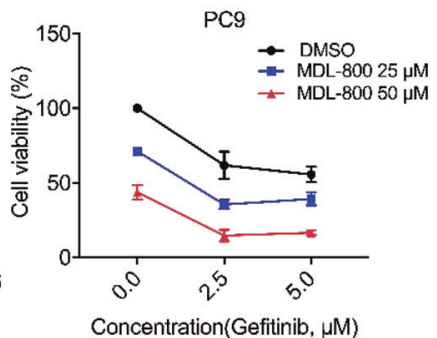

Concentration(Gefitinib, $\mu \mathrm{M}$ )
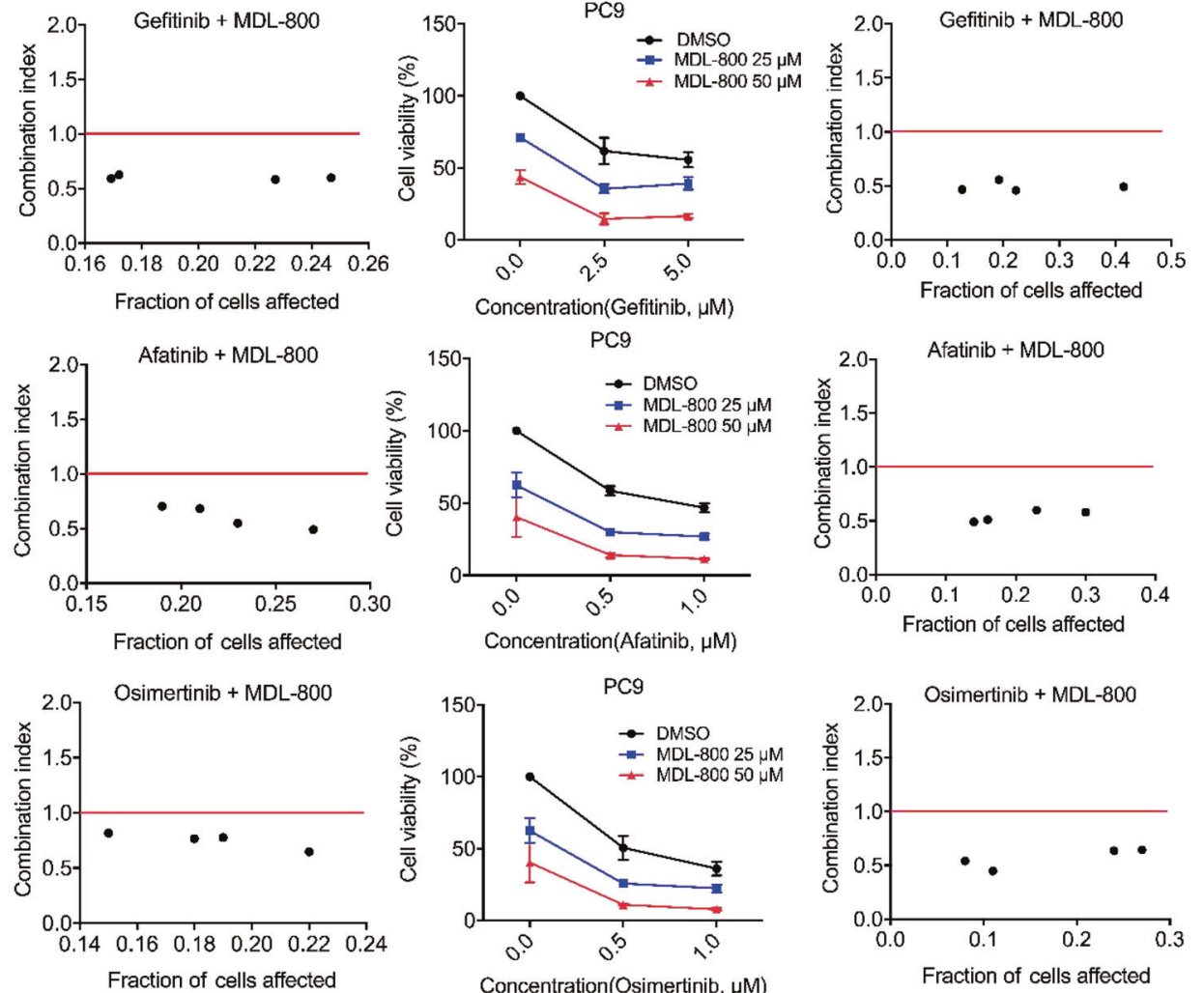

Concentration(Osimertinib, $\mu \mathrm{M}$ )

$\mathrm{NCl}-\mathrm{H} 1975 \mathrm{OR}$
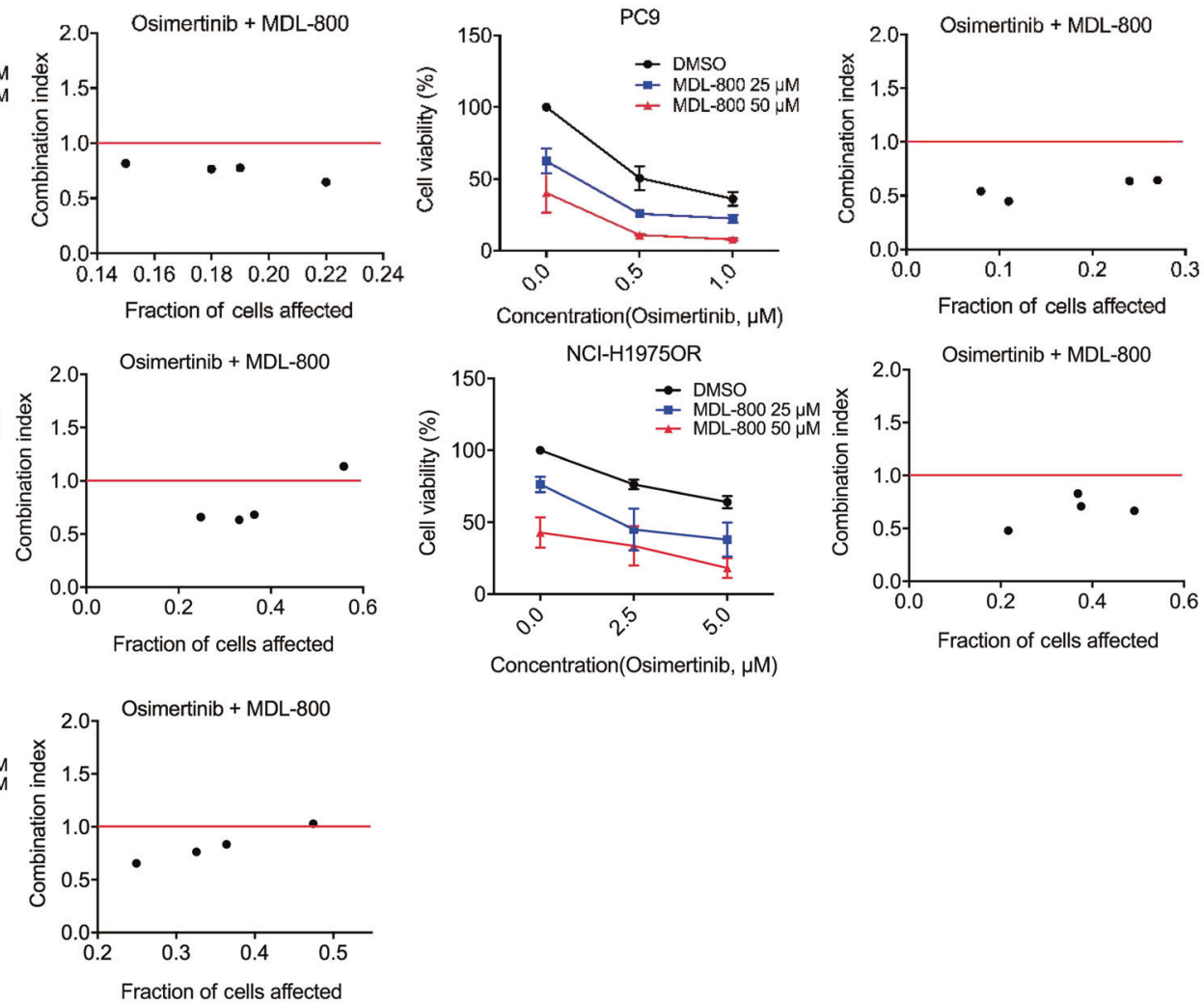

Fig. 5 MDL-800 enhances the antitumor activity of EGFR-TKIs and suppresses the MAPK pathway in NSCLC cells. Cell viability was assessed following $48 \mathrm{~h}$ of exposure to the indicated concentrations of MDL-800 alone or combined with gefitinib, afatinib, osimertinib in a HCC827 and PC9 cells, b HCC827OR and NCl-H1975OR cells, and c NSCLC patient-derived primary cells. Cl values for the various combinations were calculated using CompuSyn Version 1.0 software. Synergism, additivity, and antagonism are defined as $\mathrm{Cl}<1,=1$, and $>1$, respectively. The data are presented as the mean \pm SEM of three independent experiments.

also detected the long-term effect of MDL-800 on NSCLC cells by colony formation assays. The results showed that the colony numbers in the MDL-800-treated group were markedly decreased but MDL-800NG had little impact on the colony formation (Fig. 3d, e), further indicating that MDL-800 inhibits NSCLC cell proliferation.

MDL-800 induces SIRT6-mediated cell cycle arrest in NSCLC cells Many studies have implicated the crucial role of SIRT6 in the regulation of cell cycle progression [16, 28, 31, 45, 46]. Consistent with previous results, we found that MDL-800 remarkably arrested the cell cycle at the $\mathrm{G}_{0} / \mathrm{G}_{1}$ phase of both NSCLC cell lines (HCC827 and P(9) and had a corresponding reduction in cells in $\mathrm{G}_{2} / \mathrm{M}$ and $S$ phases, while MDL-800NG did not significantly affect the cell cycle distribution at $25 \mu \mathrm{M}$ (Fig. $4 \mathrm{a}$ and Supplementary Information Table S2). Similarly, MDL-800 exerted no observable effect on SIRT6-KO HCC827 and PC9 cells compared with control cells (Fig. 4a and Supplementary Information Table S2), suggesting that MDL activators induce a general impairment of cell cycle function in cancers. Moreover, we assessed a panel of SIRT6-mediated 

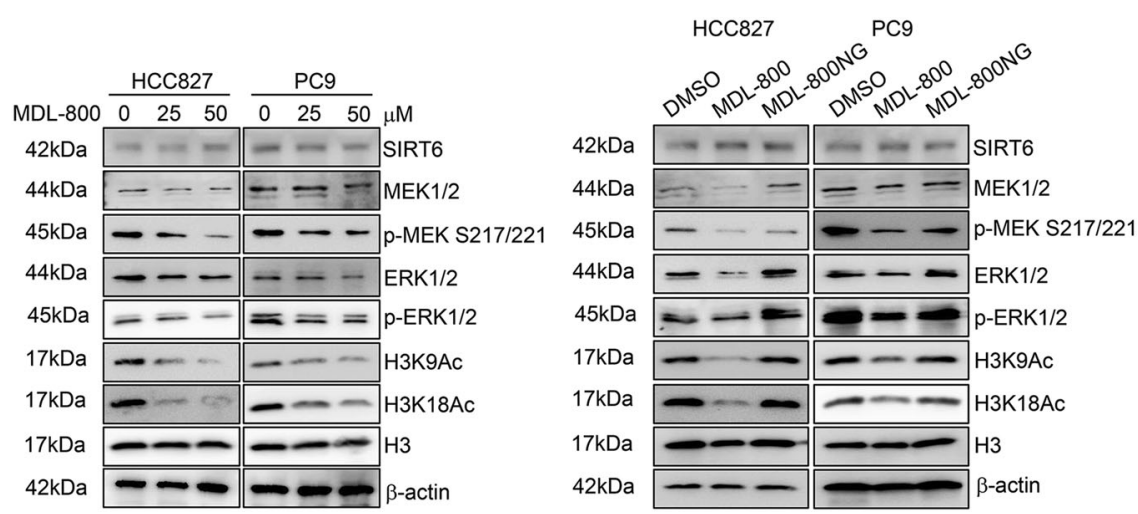

Fig. 6 Western blots of the levels of SIRT6, MEK1/2, p-MEK1/2, ERK1/2, p-ERK1/2, H3K9AC, and H3K18AC in HCC827 and PC9 cells treated with DMSO and 25 or $50 \mu \mathrm{M}$ MDL-800 (left) or DMSO and $25 \mu \mathrm{M}$ MDL-800 or MDL-800NG (right) for 48 h. Histone H3 was the internal control; $\beta$-actin was the loading control.

genes related to tumor cell cycle progression (CDC25C, PCNA, CCNA2, and CDC2) [45] and glucose metabolism (PKM2, GLUT1, and LDHA) $[29,47]$. As expected, MDL-800 potently abated the transcription of these genes in HCC827 and PC9 cells compared with that in the MDL-800NG-treated groups (Fig. 4b), indicating that MDL-800 treatment results in SIRT6-driven $\mathrm{G}_{0} / \mathrm{G}_{1}$ cell cycle arrest and glucose metabolism repression in NSCLC cells.

MDL-800 enhances the antiproliferation of EGFR-TKIs and suppresses the MAPK pathway

Targeted therapies for refractory NSCLC remain a major clinical challenge, especially for first-line EGFR-TKI therapy [3-5]. The MDL800-sensitive $\mathrm{HCC} 827, \mathrm{NCl}-\mathrm{H} 1975$, and PC9 cell lines are human EGFR-mutant NSCLC cells. The EGFR mutations are as follows: L858R in HCC827 cells, Del E746_A750 in PC9 cells, and L858R/ T790M in NCl-H1975 cells. First, we used HCC827 and PC9 cells to determine whether an SIRT6 activator is effective against NSCLC cell proliferation alone or combined with an EGFR-TKI to maximize the anticancer efficacy. As expected, CCK-8 assay results showed that MDL-800 plus each of the three generations of EGFR-TKIs (gefitinib, afatinib, and osimertinib) led to a more robust reduction in cell viability than either single agent alone in HCC827 and PC9 cells. The $\mathrm{Cl}$ analyses via the Chou-Talalay method [44] revealed a synergistic effect of MDL-800 and each of three EGFR-TKIs in NSCLC cells, in which all the Cls were below 1 (Fig. 5a). These results demonstrated that $\mathrm{MDL}-800$ sensitizes EGFR-mutant NSCLC cells to EGFR-TKIs.

To further explore whether MDL-800 could recover the drug sensitivity of OR NSCLC cells, HCC827OR and NCl-H1975OR NSCLC cells were established and cultured as described previously [4042]. We used MDL-800 alone and up to $50 \mu \mathrm{M}$ or osimertinib alone and up to $5 \mu \mathrm{M}$, and these causes no more than $50 \%$ inhibition in HCC827OR and $\mathrm{NCl}-\mathrm{H} 1975 \mathrm{OR}$ cells, respectively (Fig. 5b). The results showed that HCC827OR cells were less sensitive to MDL800 or osimertinib treatment than their parental HCC827 cells. This may be due to the strong drug resistance effect of long-term and sustained osimertinib treatment. However, the combination of MDL-800 and osimertinib suppressed the proliferation of HCC827OR and $\mathrm{NCl}-\mathrm{H} 1975 \mathrm{OR}$ cells more significantly than any single treatment, suggesting that MDL-800 effectively restored the osimertinib sensitivity of HCC827OR and NCl-H1975OR cells (Fig. 5 b). This result implied that the activation of SIRT6 by MDL800 may contribute to improving acquired osimertinib resistance in OR NSCLC cells. To further investigate the clinical potential of this combination treatment, we also isolated primary tumor cells from one NSCLC patient specimen. The CCK- 8 assay and $\mathrm{Cl}$ analysis confirmed the synergetic effect in NSCLC patient-derived primary cells cotreated with MDL-800 and osimertinib (Fig. 5c). Our data demonstrated that the combination of an SIRT6 activator and an EGFR-TKI is a potential clinical strategy for NSCLC treatment.

Many studies have demonstrated that drug resistance to EGFRTKls converges on the constitutive activation of the MAPK pathway, albeit through different mechanisms $[4,5,41,48]$. We hypothesized that MDL-800 could suppress the feedback of MAPK pathway activation, consequently enhancing the activity of EGFRTKIs in NSCLC. As depicted in Fig. 6, MDL-800 caused a reduction in the phosphorylation of MEK and ERK (p-MEK and p-ERK, respectively) in a dose-dependent manner in HCC827 and PC9 cells, while MDL-800NG did not significantly inactivate these downstream effectors. In addition, MDL-800 also increased the antiproliferation of U0126 (a specific MAPK inhibitor) in HCC827 and PC9 cells (Supplementary Information Fig. S2). These results indicated that the pharmacological activation of SIRT6 can overcome signaling redundancies and increase the sensitivity of EGFR-TKIs.

MDL-800 shows potent in vivo antitumor efficacy in NSCLC

Our cell-based assays revealed broad and robust antiproliferation of MDL-800 in NSCLC. To assess the utility of MDL-800 in NSCLC animal experiments, we characterized the pharmacokinetic properties of MDL-800. MDL-800 was administered at the indicated doses via IV bolus, oral gavage (PO), or IP injection in C57BL/6J mice ( $n=5$ mice per group). Pharmacokinetics studies showed that MDL-800 has rapid absorption and short half-life in mouse plasma (Supplementary Information Table S3). In addition, MDL-800 displayed relatively favorable bioavailability by IP injection ( $\mathrm{F} \%=73.6 \%)$.

To further evaluate the pharmacological effect of MDL-800 in vivo, we generated NSCLC CDXs. In the HCC827 CDX model, MDL-800 treatment effectively suppressed tumor growth at 80 $\mathrm{mg} / \mathrm{kg}$, but no obvious weight loss was observed (Fig. 7a-d), indicating potent in vivo antitumor activity of MDL-800. Western blot analyses of xenograft tumor tissues showed enhanced SIRT6dependent histone $\mathrm{H} 3$ deacetylation and decreased phosphorylation of MEK and ERK ( $p-M E K$ and $p$-ERK) in the groups treated with MDL-800 (Fig. 7e). Moreover, IHC staining showed that NSCLC tumor regression was associated with reduced proliferation (Ki-67) and H3K9Ac levels in xenografts after MDL-800 treatment, as well as decreased levels of p-ERK (Fig. 7f). These results revealed the potent antitumor efficacy of MDL-800-induced SIRT6 activation in NSCLC in vivo.

\section{DISCUSSION}

NSCLC is a leading cause of cancer-related death worldwide but has limited therapeutic targets. SIRT6 is a crucial epigenetic regulator of gatekeeping physiological and pathological functions, 
a

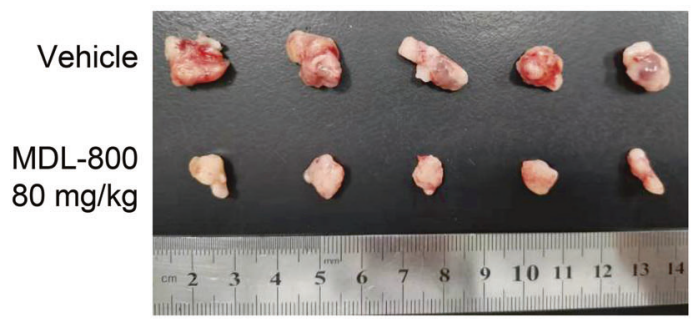

C

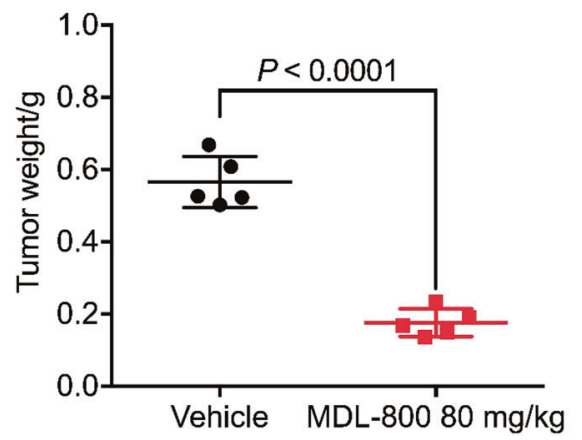

e

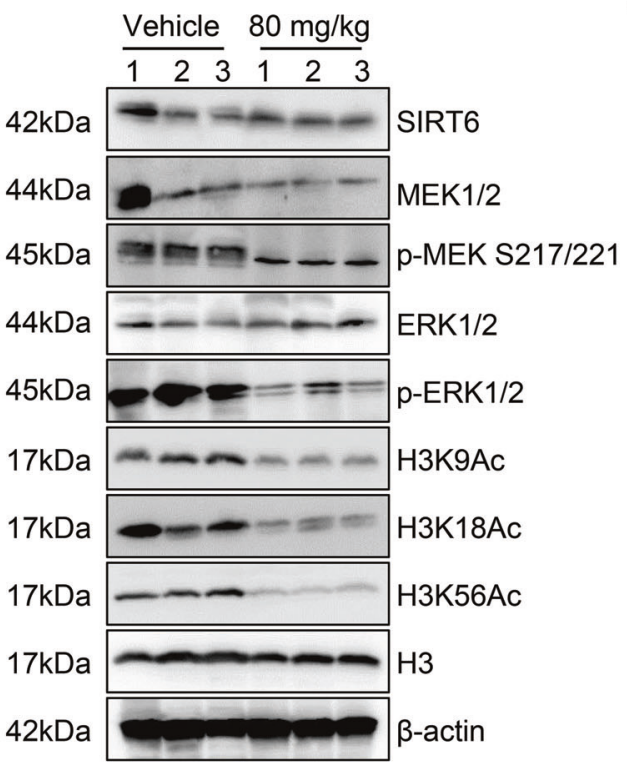

b

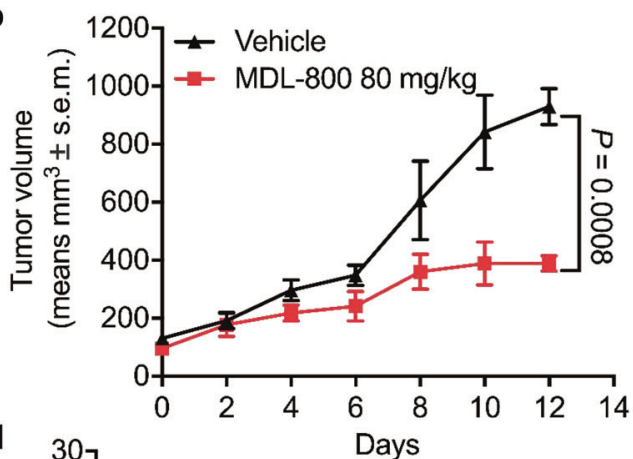

d

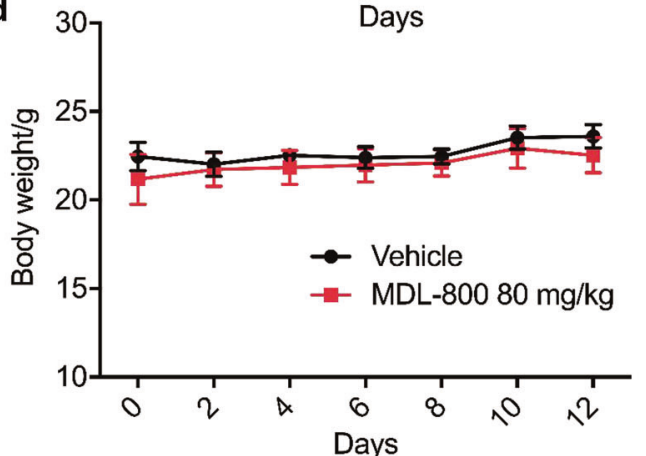

$\mathbf{f}$

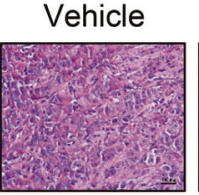

$80 \mathrm{mg} / \mathrm{kg}$
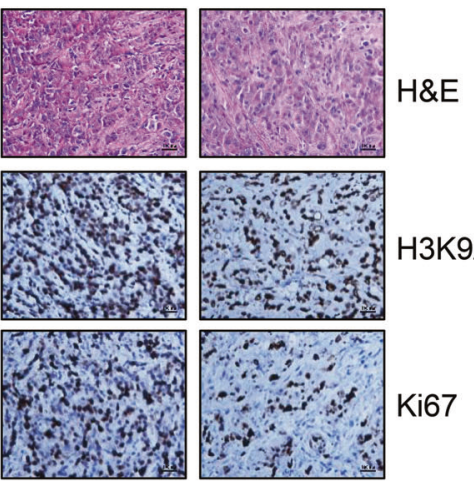

H3K9Ac
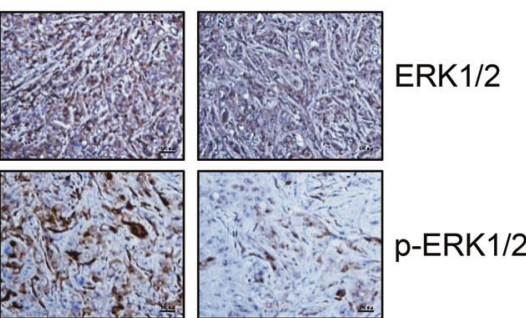

Fig. 7 MDL-800 displays robust antitumor efficacy in NSCLC cell-derived xenografts. a Representative image of HCC827 xenograft tumors dissected from nude mice treated intraperitoneally with vehicle or $80 \mathrm{mg} / \mathrm{kg}$ MDL-800 every other day for 14 days. b Volume measurements of representative xenograft tumors in different groups. The tumor volumes are shown as the mean \pm SEM of $n=5$ mice per group. $P$ values were calculated by a two-tailed Student's paired $t$ test. c Tumor weights in different groups of mice. The data are presented as the mean \pm SD of $n=$ 5 mice per group. $P$ values were determined by a two-tailed Student's unpaired $t$ test. $\mathbf{d}$ Body weights in different groups of mice (mean \pm SD of $n=5$ mice per group). e Western blots of SIRT6, MEK1/2, p-MEK1/2, ERK1/2, p-ERK1/2, H3K9Ac, H3K18Ac, and H3K56Ac levels in representative xenograft tumors from each group. Histone $\mathrm{H} 3$ was the internal control, and $\beta$-actin was the loading control. $\mathbf{f}$ Representative tissue sections from representative xenograft tumors with $\mathrm{H} \& \mathrm{E}, \mathrm{H} 3 \mathrm{~K} 9 \mathrm{Ac}$, Ki-67, ERK1/2, and p-ERK1/2 staining after treatment with vehicle or MDL-800. Representative images ( $\times 40$ magnification) are shown. Scale bars, $100 \mu \mathrm{m}$.

including tumorigenesis, via SIRT6-mediated histone H3 deacetylation $[15,17-20,31]$. Although the role of SIRT6 in cancers is cell context dependent and SIRT6 plays an oncogenic role in certain cancers, including skin cancer, squamous cell carcinoma, prostate cancer, and acute myeloid leukemia [10-14], SIRT6 mainly acts as a tumor suppressor in multiple cancers, including NSCLC $[15-20,22,23]$. Many studies have demonstrated that the downregulation of SIRT6 is closely associated with a poor prognosis in
NSCLC [21, 22], suggesting that SIRT6 could serve as a promising epigenetic target for NSCLC. However, the anticancer efficacy of SIRT6 activation in NSCLC has not been fully explored in terms of the lack of cellularly active SIRT6 activators. In this study, we demonstrated that our allosteric activator of SIRT6, MDL-800, showed favorable in vitro and in vivo anti-NSCLC activity by enhancing SIRT6 deacetylation, indicating that pharmacological activation of SIRT6 can be a promising therapy against NSCLC. 
Recent advances in targeted therapies have improved the paradigm for NSCLC treatment [3,4]. Given that EGFR is one of the most frequently mutated genes in NSCLC and is responsible for carcinogenesis, relapse, and metastasis, EGFR has been highlighted as a key target for NSCLC therapy [49]. EGFR-TKIs, from the first-generation gefitinib to the second-generation afatinib and the third-generation osimertinib, have shown profound clinical efficacy and thus have been approved for the treatment of advanced-stage EGFR-mutant NSCLC [3, 50-53]. However, prolonged treatment with EGFR-TKls often causes acquired drug resistance that limits the duration of their clinical benefit $[3-5,54]$. Thus, it is urgent to discover potential strategies for increasing sensitivity to EGFR-TKIs. Many studies have elucidated mechanisms for acquired resistance to EGFR-TKIs. For example, the emergence of T790M and C797S, which are gatekeeper mutations, accompanied by EGFR amplification, is detected in 50\% of EGFRmutant NSCLC, as well as mutational activation of downstream kinases (BRAF or PIK3CA) and amplification of related receptor tyrosine kinases (MET, ALK, or HER2) [3-5]. Mutations in EGFR can lead to constitutive activation of downstream signaling cascades, including the MAPK pathway, which regulates tumor cell proliferation and has been frequently observed to be dysregulated in NSCLC [5, 41, 48, 55, 56]. The activated MAPK pathway is believed to be a major contributor to the tumorigenesis of NSCLC and reduces the antitumor effect of EGFR-TKIs [5, 41, 48].

Notably, epigenetic alterations can be acquired during initial EGFR-TKI treatment to induce drug tolerance. Histone deacetylase (HDAC) activities can affect the survival of EGFR-TKI-resistant cells, and the combination of EGFR-TKls and HDAC inhibitors enhances anti-NSCLC efficacy [5]. It has been reported that SIRT6 inhibition could abolish the chemosensitization effect of gefitinib in NSCLC cells [57]. Interestingly, alterations in cell cycle genes often occur in NSCLC patients and are associated with poor outcomes following EGFR-TKI osimertinib treatment [54]. In addition, much evidence has revealed the crucial role of SIRT6 in the regulation of cell cycle processes $[16,28,31,45,46]$. In this study, we found that MDL-800 can efficiently suppress NSCLC cell proliferation via SIRT6-driven $\mathrm{G}_{0}$ / $\mathrm{G}_{1}$ cell cycle arrest and suppress the transcription of SIRT6-mediated genes related to tumor cell cycle progression. Due to the robust drug resistance effect of long-term and sustained osimertinib treatment, we observed that HCC827OR cells were less sensitive to MDL-800 or osimertinib treatment than their parental HCC827 cells. However, the combination of MDL-800 and osimertinib significantly restored the sensitivity of OR cells, implying that the MAPK pathway is further activated and amplified by osimertinib in resistant NSCLC cells, and the antiproliferative effect of MDL-800 and osimertinib becomes more potent. All previous studies and our study further support that pharmacological activation of SIRT6 can alleviate signaling redundancies and drug resistance of EGFR-TKIs. However, further investigations are needed to determine the exact mechanism underlying the synergistic effect of an SIRT6 activator and an EGFR-TKI. How does MDL-800, as an allosteric SIRT6 activator, inhibit the MAPK pathway and restore osimertinib sensitivity in OR NSCLC cells? What is the relationship among the activation of SIRT6, the deacetylation of histone $\mathrm{H} 3$ deacetylation, and the MAPK pathway? We need to further explore and confirm that MDL-800 enhances the activity of EGFR-TKIs by suppressing the MAPK pathway. To further identify whether pharmacological activation of SIRT6 can improve the drug resistance of EGFR-TKls in vivo, we will generate OR NSCLC CDX models with the combination treatment of an SIRT6 activator and an EGFR-TKI in future studies.

In conclusion, we demonstrated that an SIRT6 activator, MDL800 , robustly increased SIRT6-mediated histone H3 deacetylation, thus showing potent in vitro and in vivo antitumor efficacy of NSCLC. Notably, MDL-800 effectively increases the antiproliferation of EGFR-TKIs and inhibits the MAPK pathway in NSCLC. Our results provide pharmacological evidence for exploring the antiNSCLC efficacy of activating SIRT6 deacetylation and support a preclinical rationale for developing a promising strategy that combines SIRT6 activators and EGFR-TKIs to defeat NSCLC.

\section{ACKNOWLEDGEMENTS}

This research is sponsored by the National Natural Science Foundation of China (81925034, 91753117, 81721004 to JZ and 81901423 to YYC), Innovation Program of Shanghai Municipal Education Commission (2019-01-07-00-01-E00036 to JZ), Shanghai Science and Technology Innovation (19431901600 to JZ), Shanghai Health and Family Planning System Excellent Subject Leader and Excellent Young Medical Talents Training Program (2018BR12 to JZ), and Shanghai Health and Family Planning Commission (20184Y0268 to YYC).

\section{AUTHOR CONTRIBUTIONS}

$J Z$ conceived the project and supervised the project. JZ, JLS, and TXC analyzed the data and wrote the manuscript. JZ, JLS, TXC, and SBN performed the biological experiments, and YYC carried out the synthesis, purification, and characterization of the compounds. All authors discussed the results and approved the final manuscript.

\section{ADDITIONAL INFORMATION}

The online version of this article (https://doi.org/10.1038/s41401-020-0442-2) contains supplementary material, which is available to authorized users.

Competing interests: The authors declare no competing interests.

\section{REFERENCES}

1. Siegel RL, Miller KD, Jemal A. Cancer statistics, 2019. CA Cancer J Clin. 2019;69:7-34.

2. Torre LA, Bray F, Siegel RL, Ferlay J, Lortet-Tieulent J, Jemal A. Global cancer statistics, 2012. CA Cancer J Clin. 2015;65:87-108.

3. Herbst RS, Morgensztern D, Boshoff $C$. The biology and management of nonsmall cell lung cancer. Nature. 2018;553:446-54.

4. Schrank Z, Chhabra G, Lin L, Iderzorig T, Osude C, Khan N, et al. Current molecular-targeted therapies in NSCLC and their mechanism of resistance. Cancers. 2018;10:224.

5. Rotow J, Bivona TG. Understanding and targeting resistance mechanisms in NSCLC. Nat Rev Cancer. 2017;17:637-58.

6. Chalkiadaki A, Guarente L. The multifaceted functions of sirtuins in cancer. Nat Rev Cancer. 2015;15:608-24.

7. Finkel T, Deng CX, Mostoslavsky R. Recent progress in the biology and physiology of sirtuins. Nature. 2009;460:587-91.

8. Mautone N, Zwergel C, Mai A, Rotili D. Sirtuin modulators: where are we now? A review of patents from 2015 to 2019. Expert Opin Ther Pat. 2020;30:389-407. https://doi.org/10.1080/13543776.2020.1749264.

9. Kugel S, Mostoslavsky R. Chromatin and beyond: the multitasking roles for SIRT6. Trends Biochem Sci. 2014;39:72-81.

10. Ming M, Han W, Zhao B, Sundaresan NR, Deng CX, Gupta MP, et al. SIRT6 promotes COX-2 expression and acts as an oncogene in skin cancer. Cancer Res. 2014;74:5925-33.

11. Lefort K, Brooks Y, Ostano P, Cario-Andre M, Calpini V, Guinea-Viniegra J, et al. A miR-34a-SIRT6 axis in the squamous cell differentiation network. EMBO J. 2013;32:2248-63.

12. Lu CT, Hsu CM, Lin PM, Lai CC, Lin HC, Yang CH, et al. The potential of SIRT6 and SIRT7 as circulating markers for head and neck squamous cell carcinoma. Anticancer Res. 2014;34:7137-43.

13. Liu Y, Xie QR, Wang B, Shao J, Zhang T, Liu T, et al. Inhibition of SIRT6 in prostate cancer reduces cell viability and increases sensitivity to chemotherapeutics. Protein Cell. 2013;4:702-10.

14. Cagnetta A, Soncini D, Orecchioni S, Talarico G, Minetto P, Guolo F, et al. Depletion of SIRT6 enzymatic activity increases acute myeloid leukemia cells' vulnerability to DNA-damaging agents. Haematologica. 2018;103:80-90.

15. Sebastian C, Zwaans BM, Silberman DM, Gymrek M, Goren A, Zhong L, et al. The histone deacetylase SIRT6 is a tumor suppressor that controls cancer metabolism. Cell. 2012;151:1185-99.

16. Marquardt JU, Fischer K, Baus K, Kashyap A, Ma S, Krupp M, et al. Sirtuin-6dependent genetic and epigenetic alterations are associated with poor clinical outcome in hepatocellular carcinoma patients. Hepatology. 2013;58:1054-64.

17. Chen $X$, Hao B, Liu $Y$, Dai $D$, Han $G, L i ~ Y$, et al. The histone deacetylase SIRT6 suppresses the expression of the RNA-binding protein PCBP2 in glioma. Biochem Biophys Res Commun. 2014;446:364-9. 
18. Min L, Ji Y, Bakiri L, Qiu Z, Cen J, Chen X, et al. Liver cancer initiation is controlled by AP-1 through SIRT6-dependent inhibition of survivin. Nat Cell Biol. 2012;14:1203-11.

19. Ran LK, Chen Y, Zhang ZZ, Tao NN, Ren JH, Zhou L, et al. SIRT6 overexpression potentiates apoptosis evasion in hepatocellular carcinoma via BCL2associated $X$ protein-dependent apoptotic pathway. Clin Cancer Res. 2016;22:3372-82.

20. Kugel S, Sebastian C, Fitamant J, Ross KN, Saha SK, Jain E, et al. SIRT6 suppresses pancreatic cancer through control of Lin28b. Cell. 2016;165:1401-15.

21. Chen T, Sun Z, Liu F, Wang Q. RASSF1A and SIRT6 in non-small cell lung cancer: relationship with clinical outcome. Oncol Lett. 2017;14:5759-64.

22. Han Z, Liu L, Liu Y, Li S. Sirtuin SIRT6 suppresses cell proliferation through inhibition of Twist1 expression in non-small cell lung cancer. Int J Clin Exp Pathol. 2014;7:4774-81.

23. Cai Y, Sheng ZY, Liang SX. Radiosensitization effect of overexpression of adenovirus-mediated SIRT6 on A549 non-small cell lung cancer cells. Asian Pac J Cancer Prev. 2014;15:7297-301.

24. Gong J, Wang $\mathrm{H}$, Lou W, Wang G, Tao $\mathrm{H}$, Wen $\mathrm{H}$, et al. Associations of sirtuins with clinicopathological parameters and prognosis in non-small cell lung cancer. Cancer Manag Res. 2018;10:3341-56.

25. Pan PW, Feldman JL, Devries MK, Dong A, Edwards AM, Denu JM. Structure and biochemical functions of SIRT6. J Biol Chem. 2011;286:14575-87.

26. Michishita E, McCord RA, Berber E, Kioi M, Padilla-Nash H, Damian M, et al. SIRT6 is a histone $\mathrm{H} 3$ lysine 9 deacetylase that modulates telomeric chromatin. Nature. 2008;452:492-6.

27. Tasselli $L$, Xi $Y$, Zheng $W$, Tennen RI, Odrowaz $Z$, Simeoni $F$, et al. SIRT6 deacetylates H3K18ac at pericentric chromatin to prevent mitotic errors and cellular senescence. Nat Struct Mol Biol. 2016;23:434-40.

28. Michishita E, McCord RA, Boxer LD, Barber MF, Hong T, Gozani O, et al. Cell cycledependent deacetylation of telomeric histone $\mathrm{H} 3$ lysine $\mathrm{K} 56$ by human SIRT6. Cell Cycle. 2009;8:2664-6.

29. Zhong L, D'Urso A, Toiber D, Sebastian C, Henry RE, Vadysirisack DD, et al. The histone deacetylase Sirt6 regulates glucose homeostasis via Hif1alpha. Cell. 2010;140:280-93.

30. Sundaresan NR, Vasudevan P, Zhong L, Kim G, Samant S, Parekh V, et al. The sirtuin SIRT6 blocks IGF-Akt signaling and development of cardiac hypertrophy by targeting c-Jun. Nat Med. 2012;18:1643-50.

31. Liu W, Wu M, Du H, Shi X, Zhang T, Li J. SIRT6 inhibits colorectal cancer stem cell proliferation by targeting CDC25A. Oncol Lett. 2018;15:5368-74.

32. Ghosh S, Liu B, Wang Y, Hao Q, Zhou Z. Lamin A is an endogenous SIRT6 activator and promotes SIRT6-mediated DNA repair. Cell Rep. 2015;13:1396-406.

33. Feldman JL, Baeza J, Denu JM. Activation of the protein deacetylase SIRT6 by long-chain fatty acids and widespread deacylation by mammalian sirtuins. J Biol Chem. 2013;288:31350-6.

34. Schlicker C, Boanca G, Lakshminarasimhan M, Steegborn C. Structure-based development of novel sirtuin inhibitors. Aging. 2011;3:852-72.

35. You W, Rotili D, Li T-M, Kambach C, Meleshin M, Schutkowski M, et al. Structural basis of sirtuin 6 activation by synthetic small molecules. Angew Chem Int Ed. 2017;56:1007-11.

36. Rahnasto-Rilla M, Tyni J, Huovinen M, Jarho E, Kulikowicz T, Ravichandran S, et al. Natural polyphenols as sirtuin 6 modulators. Sci Rep. 2018;8:4163.

37. Huang Z, Zhao J, Deng W, Chen Y, Shang J, Song K, et al. Identification of a cellularly active SIRT6 allosteric activator. Nat Chem Biol. 2018;14:1118-26.
38. Iachettini S, Trisciuoglio D, Rotili D, Lucidi A, Salvati E, Zizza P, et al. Pharmacological activation of SIRT6 triggers lethal autophagy in human cancer cells. Cell Death Dis. 2018;9:996.

39. Huang W, Lu S, Huang Z, Liu X, Mou L, Luo Y, et al. Allosite: a method for predicting allosteric sites. Bioinformatics. 2013;29:2357-9.

40. Ogino A, Kitao $H$, Hirano $S$, Uchida A, Ishiai $M$, Kozuki $T$, et al. Emergence of epidermal growth factor receptor T790M mutation during chronic exposure to gefitinib in a non small cell lung cancer cell line. Cancer Res. 2007;67:7807-14.

41. Ma P, Fu Y, Chen M, Jing Y, Wu J, Li K, et al. Adaptive and acquired resistance to EGFR inhibitors converge on the MAPK pathway. Theranostics. 2016;6:1232-43.

42. Chen T, Luo J, Gu Y, Huang J, Luo Q, Yang Y. Comprehensive analysis of circular RNA profiling in AZD9291-resistant non-small cell lung cancer cell lines. Thorac Cancer. 2019;10:930-41.

43. Ran FA, Hsu PD, Wright J, Agarwala V, Scott DA, Zhang F. Genome engineering using the CRISPR-Cas9 system. Nat Protoc. 2013;8:2281-308.

44. Chou TC. Drug combination studies and their synergy quantification using the Chou-Talalay method. Cancer Res. 2010;70:440-6.

45. Lin Z, Yang H, Tan C, Li J, Liu Z, Quan Q, et al. USP10 antagonizes C-Myc transcriptional activation through SIRT6 stabilization to suppress tumor formation. Cell Rep. 2013;5:1639-49.

46. Ardestani PM, Liang F. Sub-cellular localization, expression and functions of Sirt6 during the cell cycle in HeLa cells. Nucleus. 2012;3:442-51.

47. Bhardwaj A, Das S. SIRT6 deacetylates PKM2 to suppress its nuclear localization and oncogenic functions. Proc Natl Acad Sci USA. 2016;113:E538.

48. Sanders HR, Albitar M. Somatic mutations of signaling genes in non-small-cell lung cancer. Cancer Genet Cytogenet. 2010;203:7-15.

49. Stella GM, Luisetti M, Inghilleri S, Cemmi F, Scabini R, Zorzetto M, et al. Targeting EGFR in non-small-cell lung cancer: lessons, experiences, strategies. Respir Med. 2012;106:173-83.

50. Li D, Ambrogio L, Shimamura T, Kubo S, Takahashi M, Chirieac LR, et al. BIBW2992, an irreversible EGFR/HER2 inhibitor highly effective in preclinical lung cancer models. Oncogene. 2008;27:4702-11.

51. Cross DA, Ashton SE, Ghiorghiu S, Eberlein C, Nebhan CA, Spitzler PJ, et al. AZD9291, an irreversible EGFR TKI, overcomes T790M-mediated resistance to EGFR inhibitors in lung cancer. Cancer Discov. 2014;4:1046-61.

52. Pedersen MW, Pedersen N, Ottesen LH, Poulsen HS. Differential response to gefitinib of cells expressing normal EGFR and the mutant EGFRvill. Br J Cancer. 2005;93:915-23.

53. Lynch TJ, Bell DW, Sordella R, Gurubhagavatula S, Okimoto RA, Brannigan BW, et al. Activating mutations in the epidermal growth factor receptor underlying responsiveness of non-small-cell lung cancer to gefitinib. $\mathrm{N}$ Engl J Med. 2004;350:2129-39.

54. Leonetti A, Sharma S, Minari R, Perego P, Giovannetti E, Tiseo M. Resistance mechanisms to osimertinib in EGFR-mutated non-small cell lung cancer. $\mathrm{Br} J$ Cancer. 2019;121:725-37.

55. Roberts PJ, Der CJ. Targeting the Raf-MEK-ERK mitogen-activated protein kinase cascade for the treatment of cancer. Oncogene. 2007;26:3291-310.

56. Chang F, Steelman LS, Shelton JG, Lee JT, Navolanic PM, Blalock WL, Franklin R, et al. Regulation of cell cycle progression and apoptosis by the Ras/Raf/MEK/ERK pathway (Review). Int J Oncol. 2003;22:469-80.

57. Dai PC, Liu DL, Zhang L, Ye J, Wang Q, Zhang HW, et al. Astragaloside IV sensitizes non-small cell lung cancer cells to gefitinib potentially via regulation of SIRT6. Tumour Biol. 2017:39:1010428317697555. 